\title{
Mitochondria chaperone GRP75 moonlighting as a cell cycle controller to derail endocytosis provides an opportunity for nanomicrosphere intracellular delivery
}

\author{
Zhihui Gao ${ }^{1, *}$, Xiuran Niu ${ }^{1, *}$, Qing Zhang ${ }^{2, *}$, Hang Chen ${ }^{1}$, Aiai Gao ${ }^{1}$, Shanshan $\mathbf{Q i}^{1}$, \\ Rong Xiang ${ }^{1}$, Mattias Belting ${ }^{3}$ and Sihe Zhang ${ }^{1}$ \\ ${ }^{1}$ Department of Biochemistry \& Cell Biology, School of Medicine, Nankai University, Tianjin, China \\ ${ }^{2}$ Department of Clinical Laboratory, Cancer Hospital of Tianjin Medical University, Tianjin, China \\ ${ }^{3}$ Department of Clinical Sciences, Section of Oncology, Lund University, Lund, Sweden \\ *These authors have contributed equally to this work \\ Correspondence to: Sihe Zhang, email: sihezhang@nankai.edu.cn \\ Keywords: GRP75, cell cycle, clathrin-mediated endocytosis, clathrin-independent endocytosis, nanomicrosphere \\ Received: February 06, $2017 \quad$ Accepted: March 27, $2017 \quad$ Published: April 19, 2017 \\ Copyright: Gao et al. This is an open-access article distributed under the terms of the Creative Commons Attribution License 3.0 \\ (CC BY 3.0), which permits unrestricted use, distribution, and reproduction in any medium, provided the original author and source \\ are credited.
}

\section{ABSTRACT}

Understanding how cancer cells regulate endocytosis during the cell cycle could lead us to capitalize this event pharmacologically. Although certain endocytosis pathways are attenuated during mitosis, the endocytosis shift and regulation during the cell cycle have not been well clarified. The conventional concept of glucose-regulated proteins (GRPs) as protein folding chaperones was updated by discoveries that translocated GRPs assume moonlighting functions that modify the immune response, regulate viral release, and control intracellular trafficking. In this study, GRP75, a mitochondria matrix chaperone, was discovered to be highly expressed in mitotic cancer cells. Using synchronized cell models and the GRP75 gene knockdown and ectopic overexpression strategy, we showed that: (1) clathrin-mediated endocytosis (CME) was inhibited whereas clathrinindependent endocytosis (CIE) was unchanged or even up-regulated in the cell cycle M-phase; (2) GRP75 inhibited CME but promoted CIE in the M-phase, which is largely due to its high expression in cancer cell mitochondria; (3) GRP75 targeting by its small molecular inhibitor MKT-077 enhanced cell cycle G1 phase-privileged CME, which provides an opportunity for intracellular delivery of nanomicrospheres sized from $40 \mathrm{~nm}$ to 100 $\mathrm{nm}$. Together, our results revealed that GRP75 moonlights as a cell cycle controller and endocytosis regulator in cancer cells, and thus has potential as a novel interference target for nanoparticle drugs delivery into dormant cancer cells.

\section{INTRODUCTION}

A moonlighting protein is a single protein with multiple functions that are not a result of gene fusions, splice variants, proteolytic fragments, families of homologous proteins, or promiscuous enzyme activities $[1,2]$. Several hundred moonlighting proteins have been experimentally identified. Some can simultaneously perform unrelated functions, but others can switch functions due to changes including the cell type, cellular redox status, subcellular location, oligomeric state, and binders of the protein [3-5].
There is evidence that a moonlighting protein can provide a connection between distinct biochemical processes, help the cell to adapt to microenvironmental stress, and contribute to phenotype-corrupted diseases [6-8].

Chaperone proteins are traditionally known as cytoplasmic proteins that prevent clients from misfolding, promote refolding, and correct the assembly of unfolded polypeptides. However, accumulating evidence showed that they have a growing number of moonlighting functions in and/or outside the cell. This is particularly true for the bacterial cell surface-located Cpn60 and DnaK, which 
generally function as adhesins for a range of host components including plasminogen, glycosphinngolipids, mucins, and CD43 [9-18]. These cell surface-resident Hsp60 and Hsp70 not only control bacterial-host cell interaction, but also stimulate cytokine production, thus exhibiting distinct biological functions [6]. The eukaryotic cell secreted Hsp90 was reported to bind with and stabilize matrix metalloproteinase (MMPs) activation, which contributes to angiogenesis, cancer cell invasiveness, and wound-healing [19-22]. When shuttling into the nucleus, Hsp90 was found to alter MMPs and E-cadherin production, giving rise to a epithelial-mesenchymal transition and enhanced cancer cell motility [23]. Another example of a eukaryotic chaperone is Hsp60 which moonlights as a cell surface receptor for HDL and apoA-II [24]. Interesting, the capacitation of murine sperm requires the presence of cell surface Hsp60 and its tyrosine phosphorylation [25]. All these suggest that the subcellular localization change of cytoplasmic chaperones determines their moonlighting function. However, no organelle-resident chaperone has been investigated.

GRP75 (mortalin/PBP74/mtHSP70), a mitochondrial matrix-resident chaperone protein, is often detected in different compartments of cancer cells. Although GRP75 was originally identified as having a chaperone role in bioenergetics-associated transport and refolding of clients inside mitochondria, it also acts as a guardian against senescence and apoptosis from various stresses, or serves as a safeguard to promote cell proliferation and survival, suggesting its multiple additional functions alter in cancer cells [26, 27]. Notably, GRP75 has recently been characterized as an important cell cycle controller in tumor cells. GRP75 depletion or inhibition causes G0/G1-phase cell cycle accumulation in medullary thyroid carcinoma cells $[23,28]$. GRP75 knock down or blockage induces G2/M-phase cell cycle arrest in B-Raf/K-Ras-mutated melanoma and lung cancer cells[29, 30]. Furthermore, the role of GRP75 in G2/M-phase enrichment was also demonstrated in ovarian cancer cells [26]. Previously we accidentally found that GRP75 is enriched as a functional constituent in heparan sulfate proteoglycan (HSPG)mediated and membrane raft-associated endocytosis vesicles in cervix cancer cells [31]. More recently, we further found that GRP75 promotes clathrin-independent endocytosis (CIE) but inhibits clathrin-mediated endocytosis (CME) by the $\mathrm{Cdc} 42$ and RhoA concurrent activation mechanism [32]. Given that endocytosis and the cell cycle are tightly linked and several studies indicated that certain endocytosis pathways are shut down during mitosis [33-38], the endocytosis regulation function of GRP75 may be modulated during the cell division process.

In this study, we investigated whether GRP75 moonlights as a cell cycle control and endocytosis regulator in HeLa and Cos-7 cells. We also determined the effect of GRP75 subcellular localization on its cell cycle control and endocytosis regulation function, and further explored the possibility of potential delivery of different size nanomicrospheres by GRP75 targeting. Our data showed that: (1) CME was inhibited whereas CIE was unchanged or even up-regulated in the M-phase of the cell cycle; (2) GRP75 inhibited CME but promoted CIE in the M-phase, which is due to its high expression in cancer cell mitochondria; and (3) GRP75 targeting enhanced cell cycle G1-phase-privileged CME, which provides an opportunity for intracellular delivery of different size nanomicrospheres. Together, our results reveal that GRP75 moonlighting functions as a cell cycle controller and endocytosis regulator in cancer cell, and thus has potential as a novel interference target for nanoparticle intracellular drug delivery.

\section{RESULTS}

\section{Reduced CME versus unaltered CIE in the M-phase of the cell cycle}

It is debated whether endocytosis is totally inactive in mitosis [34, 36, 37]. We first checked endocytosis variation in unperturbed HeLa and Cos-7 cells. Confocal imaging analysis showed that the uptake of the CME marker Tfn was almost shutdown in mitotic cells (Figures 1A, 1B). However, the uptake of the membrane raft marker CTxB was slightly increased in a partial population of mitotic cells (Figures 1A, 1C). In contrast, only a small uptake difference of the $\alpha \mathrm{HS}$ complex between mitotic- and interphase-cells was observed (Figures 1A, 1D). In addition, no macropinocytosis was detected unless cells were heavily starved for a long time (Supplementary Figure 5). To clarify this variation, we next synchronized cells in different subphases by chemical drug pretreatment (Supplementary Figure 1), and then determined the uptakes in arrested cell cycle phases by flow cytometry measurement. The results showed that, compared with the uptake in atorvastatininduced G1-phase cells, Tfn uptake was decreased in the double thymidine-blocked S-phase and markedly decreased in the nocodazole/colcomid-induced M-phase (Figure 1E). Conversely, the uptake of CTxB was slightly increased in the Ro3306-induced G2-phase and significantly enhanced in induced M-phase cells (Figure 1F). Only a limited uptake increase of the $\alpha \mathrm{HS}$ complex was observed in induced G2/ M-phase cells (Figure 1G). These results suggest that CME is decreased whereas CIE remained constant or was even increased in the cell cycle M-phase.

\section{GRP75 is highly expressed in mitochondria in the G2/M-phase}

As membrane trafficking dynamically varies during cell division [33, 39] and our previous studies showed that GRP75 is essential to raft-associated endocytosis regulation [31,32], we determined the expression change of GRP75 together with endocytic components in subphases of the cell cycle. As predicated by Cyclebase analysis, high-expression of the GRP75 homologue 
A
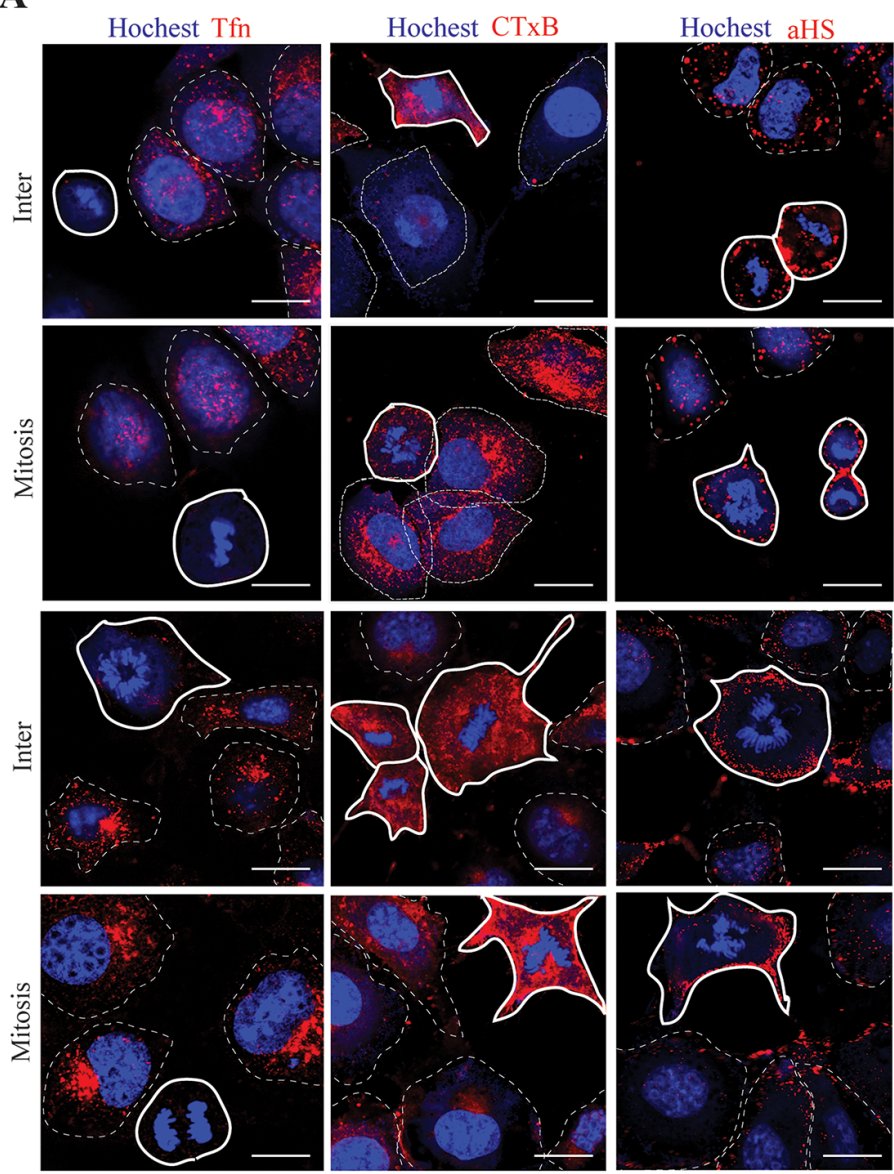
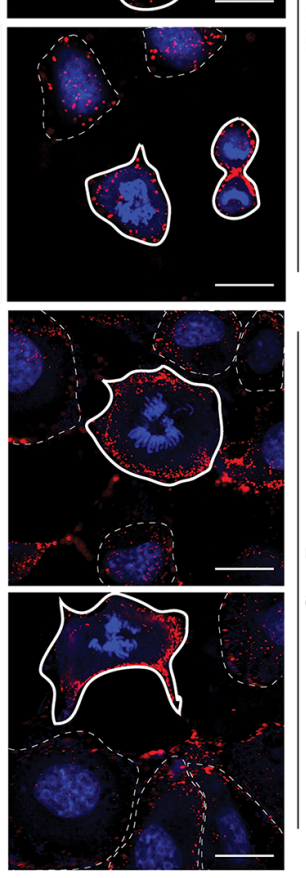

B
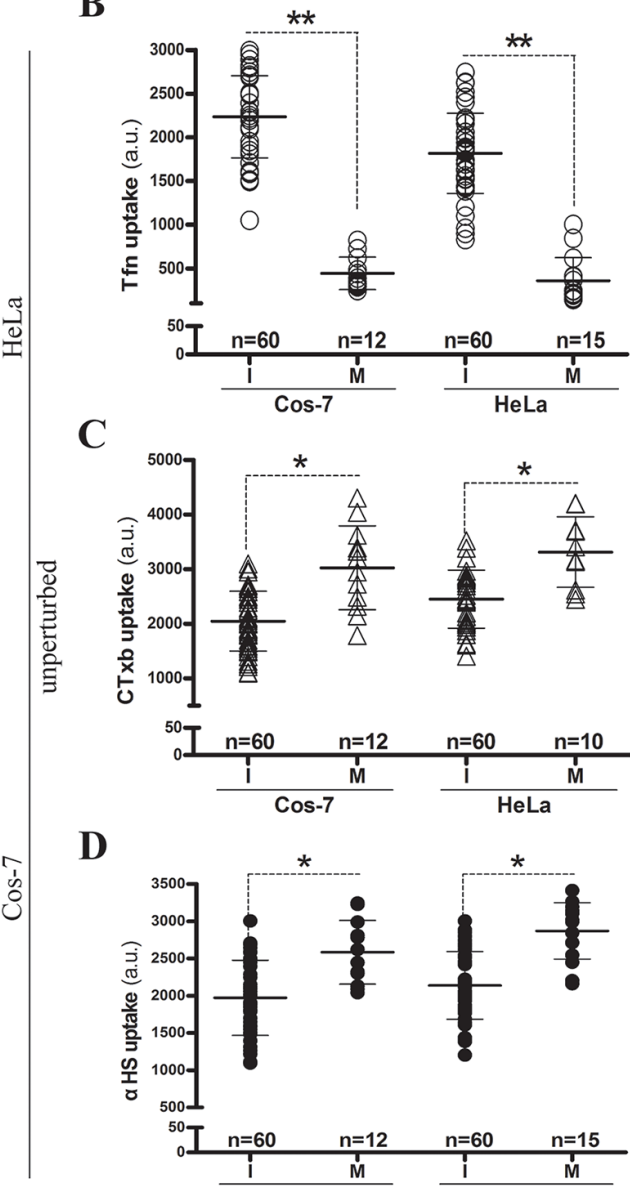

C

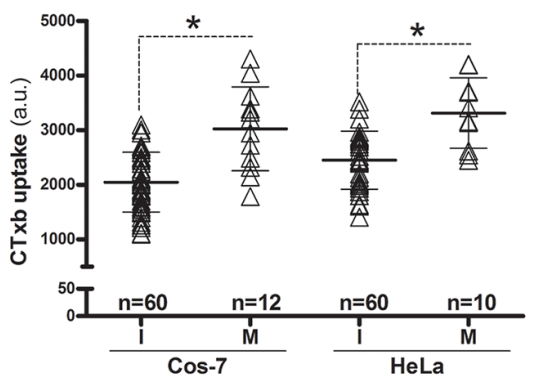

D

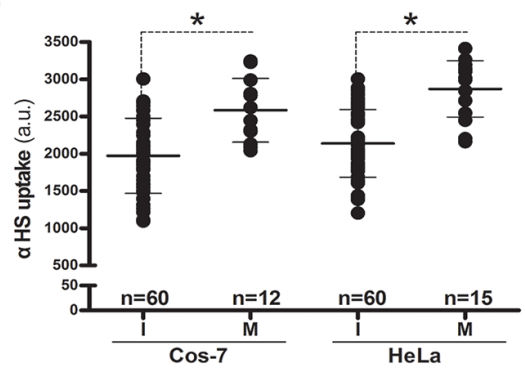

G
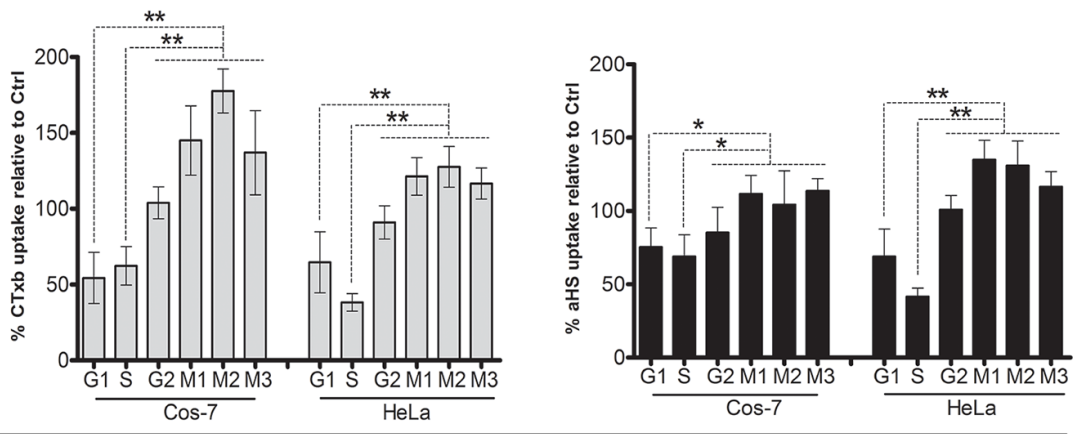

perturbed

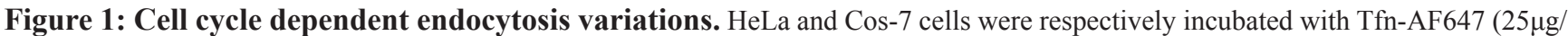

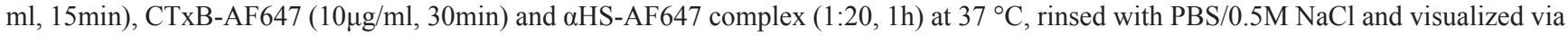
confocal microscopy. Representative images from three independent experiments are shown in (A). Scale bar: $20 \mathrm{um}$. Scatterplots depict the uptake variability of indicated ligands in single cell populations. The uptake quantification for each cell was described in 'Materials and methods', and uptake levels in M or I phase cells are summarized in (B), (C) and (D). 60 cells were counted for the I phase (polygons with thin dotted line) and $\geq 10$ cells were counted for the $\mathrm{M}$ phase (polygons with bold solid line) in each experiment, $\mathrm{n}=3$. Phase-arrested cells were induced by drug treatments as follows: the G1-phase was induced by atorvastatin, the S-phase was induced by double thymidine block, the G2-phase was induced by RO3306 treatment, and the M-phase was enriched by double thymidine block with further nocodazole incubation (M1) or with further 10\% FBS stimulation (M2) or with colcomid incubation (M3). Arrested cells were incubated respectively with indicated drugs at $37{ }^{\circ} \mathrm{C}$, and uptakes were immediately analyzed via FACS. The uptake quantification of ligands in any sub-phase was corrected by the corresponding cell cycle phase percentage, and the uptake levels are summarized in (E), (F) and (G). 10,000 cells were counted per treatment in each experiment, $\mathrm{n}=3$. Statistically significant differences in relation to the control (no drug treated cells) are shown: $* * P<0.01, * P<0.05$. 
HSP7M frequently appeared in the G2-phase. However, high-expression of the $\mathrm{CCV}$ (clathrin-coated vesicle) dissociation factor HSC70 was mainly distributed in the G1-phase. High expression of clathrin was scarcely distributed in the M-phase, whereas highly-expressed TfnR appeared in the G1-phase. High expression of caveolin-1, the negative regulator of raft-dependent endocytosis, was frequently present in M- and G1phases, which was in contrast to the high expression of raft endocytosis-dispensable caveolin-2 in the G1-phase (Figure 2A). Western blot analysis of cell fractions showed that the mitochondria-resident GRP75 was markedly higher expressed in S-, G2-, and M-phases than in the G1-phase. In contrast, the mitochondria- and membraneassociated HSC70 was sharply reduced in the M-phase. Although total cell lysate-derived and mitochondrial TfnR expression in S-, G2-, and M-phases doubled, membraneresident $\mathrm{TfnR}$ expression was halved. The half reduction trend in these phases appeared similar to lysate-derived clathrin. Unexpectedly, expression of lysate-derived and mitochondrial caveolin-1 in G2- and M-phases doubled. However expression of membrane-resident caveolin-1 in the corresponding phases significantly decreased (Figure 2B). Furthermore, staining of cells by its rhodacyanine dye inhibitor MKT-077 at high concentrations or by its specific $\mathrm{Ab}$, confirmed that mitochondria resident GRP75 was highly expressed in mitotic cells (Figures 2C, 2D). All these results indicate that GRP75 is highly expressed in the mitochondrial fraction in G2- and M-phases.

\section{Mito-trafficked GRP75 promotes cell cycle M-phase accumulation}

To determine the role of mitochondria resident GRP75 on the cell cycle distribution, we first constructed $\mathrm{N}$-/C-terminal EGFP-fused GRP75 plasmids with/without a signal peptide for directed overexpression (Figure 3A). Bioinformatics prediction showed that only the GRP75EGFP construct could be possible to target-express in mitochondria (Supplementary Table 1). Western blot results showed that the GRP75-EGFP construct was dominantly expressed in the mitochondria fraction with the predicted molecular weight (Figures 3B, 3C). This exclusive mitochondria-trafficking expression was further validated by confocal co-localization analysis based on mitoTracker Red labeling and anti-EGFP Ab staining (Figure 3D). After adjusting the transfected plasmids concentration to maintain an even expression of fusion proteins, flow cytometry analysis of the EGFP-positive cells showed that only GRP75-EGFP overexpression most significantly induced cell cycle accumulation in the M-phase (Figures 4E, 4F). Using the EGFPlabeled lentiviral shRNA expression system (shGRP75) that targeted different mRNA regions, GRP75 was substantially depleted (Supplementary Figure 2A), and cell cycle analysis showed that GRP75 depletion markedly arrested the cell cycle in the G1-phase (Figures 4C, 4D). We also treated both cells with the GRP75 inhibitor MKT077, and found that MKT-077 treatment only significantly increased the HeLa cell population in the G1 phase in a dose-dependent manner (Figures 4A, 4B; Supplementary Table 2). These results suggest that GRP75 traffickingexpression in mitochondria promotes the accumulation of cancer cells in the M-phase.

\section{Mito-trafficked GRP75 inhibits CME but promotes CIE in the M-phase}

Since endocytosis variation is pronounced during cell division, the impact of the cell cycle-dependent expression of GRP75 on the endocytosis pathway was then examined. Confocal imaging analysis of EGFP-positive cells showed that GRP75-EGFP overexpression markedly increased the uptake of CTxB (average increases of $22 \%$ in the I-phase and of 59\% in the M-phase), increased the uptake of the aHS complex (average increases of $49 \%$ in the I-phase and of $100 \%$ in the M-phase), but significantly decreased the uptake of Tfn (average decreases of 30\% in the I-phase and $41 \%$ in the M-phase), and all induced more uptake changes in the mitotic phase than that in the interphase (Figures 5A-5D). In contrast, overexpression of other GRP75-fused constructs resulted in little changes to the uptakes. These GRP75 mitochondria-localizationinduced effects on cell cycle dependent endocytosis were similarly observed in flow cytometry quantification results (Figure 5E). To further confirm this GRP75-dominated effect, EGFP-labeled shGRP75 stable cell lines were used. Confocal and flow cytometry quantification analyses of these cells showed that GRP75 depletion significantly increased the uptake of Tfn in the interphase (average increments $45 \%$ and $78 \%$, respectively), more markedly decreased the uptake of CTxB in the mitotic phase (average decrements $275 \%$ and $78 \%$, respectively) than that in the interphase (average decrements $65 \%$ and $42 \%$, respectively), and limited the uptakes of the aHS complex more in the mitotic phase (average decrements of $61 \%$ and 54\%, respectively) (Figure 6, Supplementary Figure 6). Further treatment of cells with the GRP75 inhibitor MKT-077 obtained similar results (Figure 7). These results together with the aforementioned data suggest that mitochondria-trafficked GRP75 significantly promotes CIE but inhibits CME primarily in the M-phase.

\section{GRP75 targeting enhances G1 phase-privileged nanomicrosphere uptake}

To examine whether GRP75-induced cell cycleprivileged endocytosis can be capitalized, we tested its inhibitor to improve the delivery efficiency of nanomicrospheres sized from $20 \mathrm{~nm}$ to $2 \mathrm{um}$ in diameter. Cytometry quantification results showed that HeLa cells took up fluorescent microspheres in both a time- and 

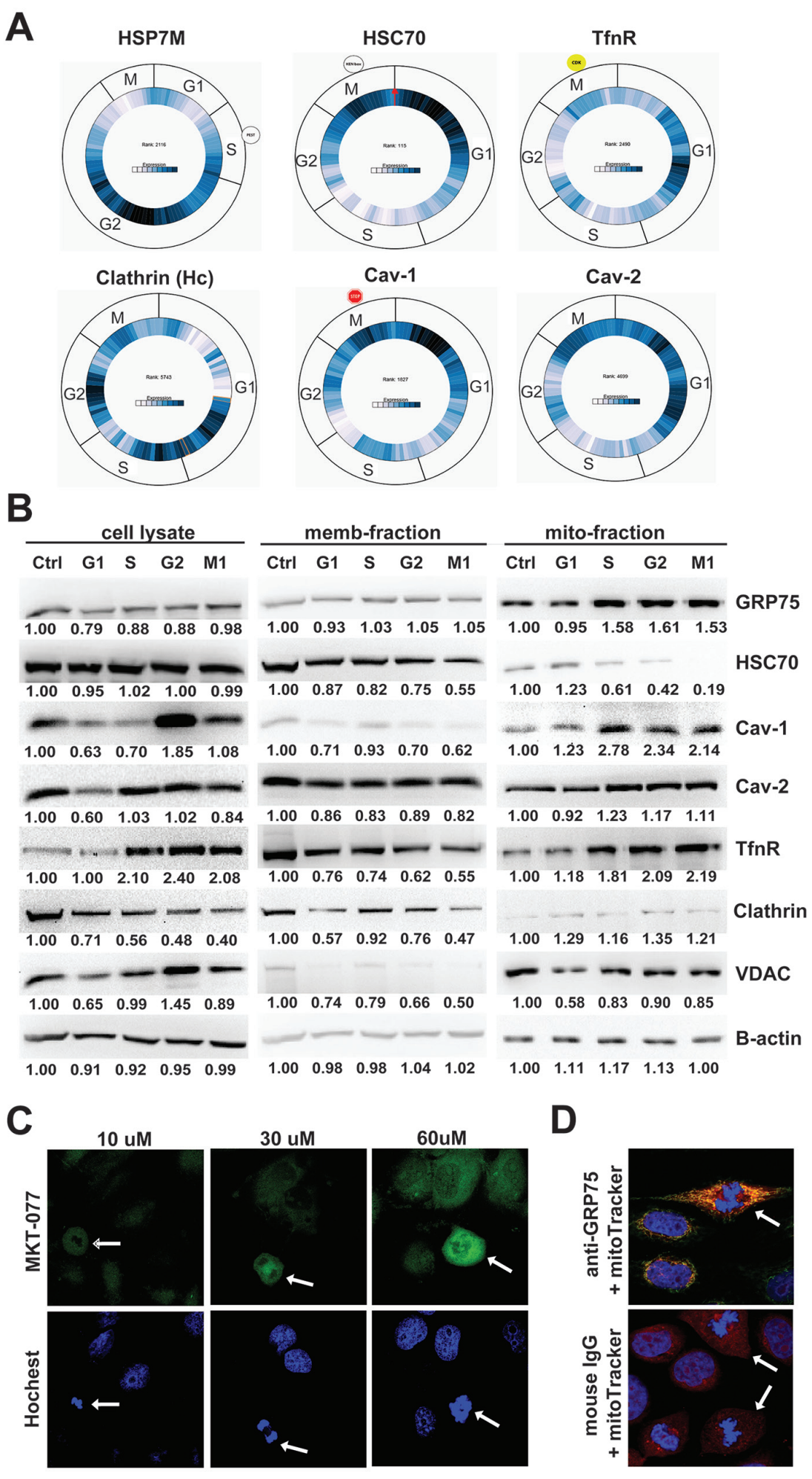

Figure 2: High expression of mitochondrial GRP75 in G2/M-phases. (A) Predication of expression changes of HSP7M (GRP75 homologue), Hsc70, TfnR, clathrin, and caveolin-1/-2 in sub-phases of cell cycle usingCyclebase 3.0 analysis (dark blue content indexes the expression level of $\mathrm{mRNA}$ /protein during the cell cycle); (B) Western blot determined the expression level of those mentioned above in synchronized HeLa subcellular fractions. lysate-: whole cell lysate, memb-: membrane lysate, and mito-: mitochordrian lysate. Protein brands were quantified by Image $\mathrm{J}$ software and the expression ratio (compared to that of non-treated cells, Ctrl, set as 1) in the sub-phase is correspondingly marked below. Mitotic (arrow pointing) and interphase HeLa cells were stained by concentration-increased MTK-077 dye (C), or co-stained by anti-GRP75 antibody (1:100) together with the mitochondrial marker mitoTracker®Red (300nM) (D). Similar results were found in Cos-7 cells (Data not shown). 
size-dependent manner (Supplementary Figure 3). Little uptake was seen for particles sized $2 \mu \mathrm{m}$. Pretreating the cells with the CME inhibitor chlorpromazine significantly decreased the uptake of microspheres of size $40 \mathrm{~nm}$ and $100 \mathrm{~nm}$ to $52 \pm 9 \%$ and $38 \pm 4 \%$, respectively, whereas the uptake of those sized $20 \mathrm{~nm}$ and $500 \mathrm{~nm}$ was not significantly altered. Pretreating the cells with the caveolae-disrupting agent filipin only reduced the uptake of $500 \mathrm{~nm}$ microspheres to $45 \pm 6 \%$, but brought no uptake changes to other sizes of microspheres. In contrast, MKT077 treatment markedly enhanced the uptakes of $40 \mathrm{~nm}$ and $100 \mathrm{~nm}$ microspheres to $144 \pm 11 \%$ and $178 \pm 21 \%$, respectively, but significantly impaired the uptakes of 20 $\mathrm{nm}$ and $500 \mathrm{~nm}$ microspheres to $64 \pm 12 \%$ and $55 \pm 10 \%$, respectively (Figure 8A). Further checking the uptakes in shGRP75 stable cell lines showed that internalized microspheres of $100 \mathrm{~nm}$ were markedly increased, which was in contrast with the reduced uptake of $500 \mathrm{~nm}$ microspheres. The distinct uptake changes of microspheres induced by GRP75 knock-down were efficiently rescued by exogenous GRP75 overexpression (Figure 8B). These results indicate that cells internalized $40 \mathrm{~nm}$ to $100 \mathrm{~nm}$ microspheres via the CME pathway, internalized $500 \mathrm{~nm}$ microspheres mainly via the CvME pathway, and that targeting GRP75 enhanced CME of nanomicrospheres sized from $40 \mathrm{~nm}$ to $100 \mathrm{~nm}$.

Since nanoparticle uptake is influenced by the cell cycle phase $[40,41]$, the endocytosis pathway variation in cell cycle stages may lead to the differential uptake of certain particles. Comparing the uptakes in synchronized $\mathrm{HeLa}$ cells, it was found that $100 \mathrm{~nm}$ microspheres were most dominantly concentrated in the cell cycle G1-phase, whereas $500 \mathrm{~nm}$ microspheres were mainly accumulated in G1- and M-phases (Figure 8C). These well agree with the afore-obtained results, suggesting that enhanced uptake of $100 \mathrm{~nm}$ microspheres may be largely due to the G1-phase retention effect. To further examine whether GRP75 targeting can potentiate this effect, we treated the cells with different drugs combinations. Unexpectedly, MKT-077 treatment did not augment atorvastatin-induced G1-phase uptake-enhancement of $100 \mathrm{~nm}$ microspheres. MBCD was frequently shown
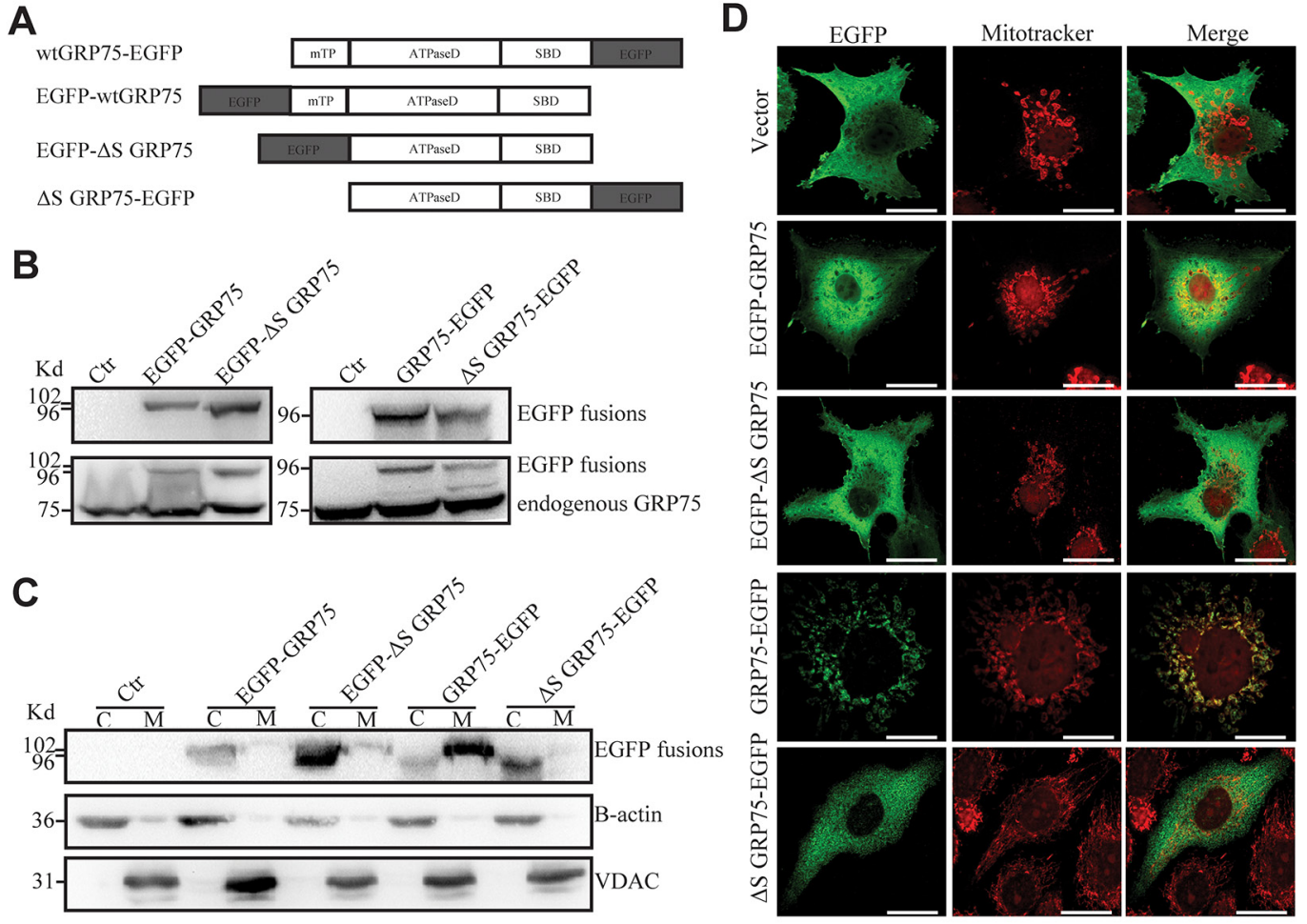

Figure 3: Signal peptide directed GRP75 expression-trafficked into mitochondria. (A) Schematic representation of C-/Nterminal EGFP-fused GRP75 constructs with/without mitochondrial-targeting signal peptides. wt: wild type. mTP: mitochondrial-targeting signal peptide. $\triangle \mathrm{S}$ : without signal peptide. ATPaseD: ATPase domain. SBD: substrate-binding domain. (B) HeLa cells were transfected with GRP75 constructs as listed above. Forty-eight hours post-transfection, the cell lysates were analyzed through SDS-PAGE followed by Western blotting with rabbit anti-GFP Ab and mouse anti-GRP75 Ab as described in Materials and Methods. (C) The cytoplasm (C) and mitochondria (M) fractions of transfected HeLa cells were analyzed by Western blotting with rabbit anti-GFP Ab (up row), anti-B-actin Ab (middle row), and anti-VDAC Ab (down row), respectively. (D) Transfected HeLa cells were first stained with mitoTrcker (300nM) for 10 min at $37^{\circ} \mathrm{C}$ for mitochondria labeling (red color). After fixation and permeabilization, cells were sequentially stained with rabbit anti-GFP $\mathrm{Ab}$ (1:500) and then with anti-rabbit AF488 (1:1000). The co-stained cells were viewed under a confocal microscope. Representative cell images show the contrast distribution of exogenous EGFP-fused proteins with mitochondria. Scale bar, $20 \mathrm{um}$. 
to deplete cholesterol from cell membranes thereby altering the transport of many drug molecules through diffusion or receptor meditated uptake [42]. When cells were treated with MKT-077 combined with MBCD, the uptake of $100 \mathrm{~nm}$ microspheres increased dramatically to $220 \pm 21 \%$ as compared to either agent alone (Figure 8D). On the contrary, no synergistic effect but counteraction phenomena was observed in MBCD combined with atorvastatin treatment. Interestingly, these contrast effects induced by either single drug pretreatment or by MKT077 combined with MBCD/atorvastatin pretreatment were similarly observed in mito-GRP75 low-expressed
WI-38 cells (Figures 8D, Supplementary Figure 4), where the whole uptake of $100 \mathrm{~nm}$ microspheres was fairly low (Figure 8D).

\section{DISCUSSION}

The conventional concept of glucose-regulated proteins (GRPs) as protein folding chaperones was updated by discoveries that GRPs promote tumor proliferation, metastasis, drug resistance, and immunotherapy. As a mitochondria matrix dominant chaperone highly expressed in cancer cells and contributing to carcinogenesis,
A
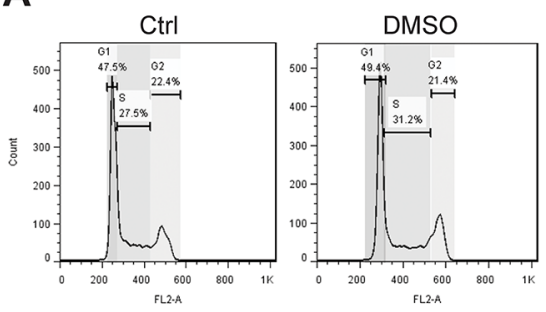

C

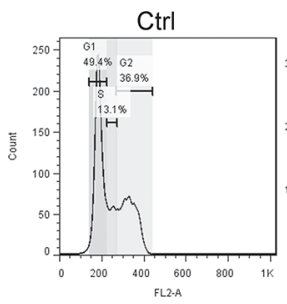

E

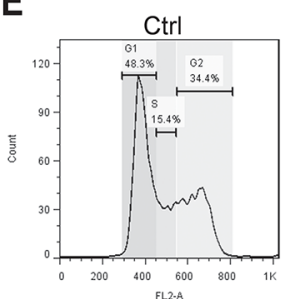
EGFP- $\triangle S$ GRP75

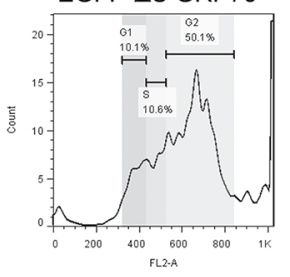

NC-shRNA
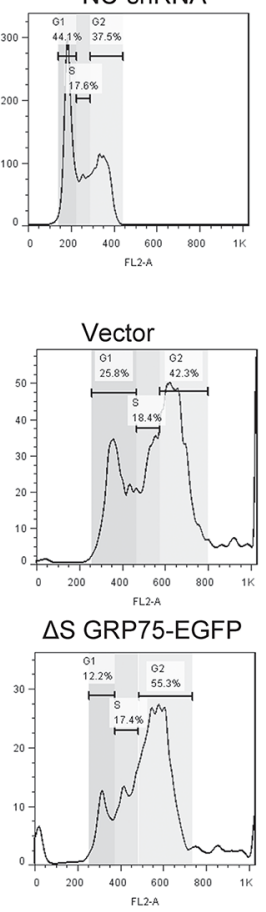
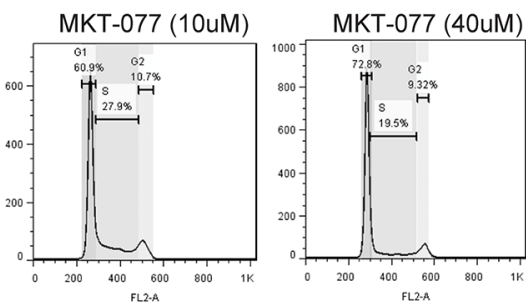

B

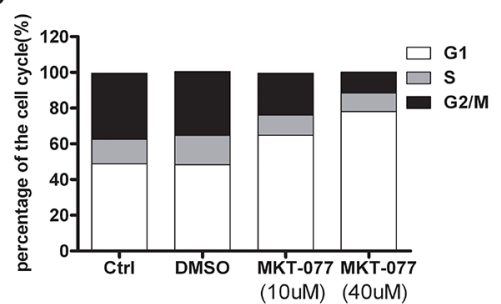

D

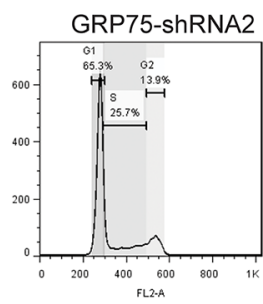

+ GRP75 OE
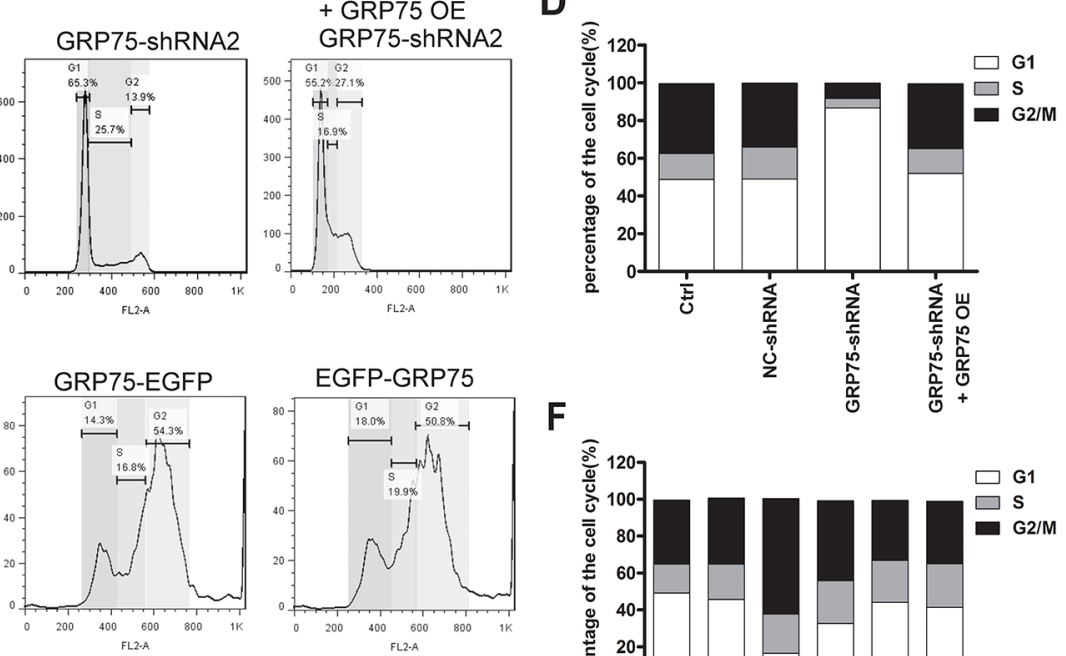

F

G

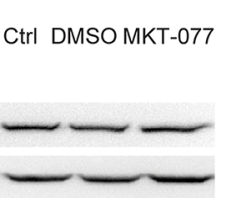

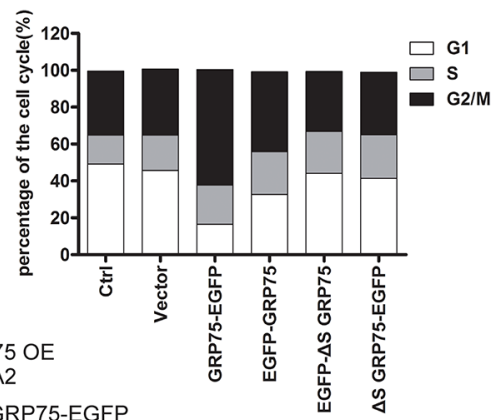

Figure 4: GRP75 expression promotes cell cycle enrichment in the M-phase. (A) HeLa cells were treated with serially increasing doses of MKT-077 (5, 10, 20, and 40uM) for 24 hours prior to cell cycle analysis by propidium iodide staining and flow cytometry. (C) Cell cycle distribution was determined in HeLa cells stably transduced with lentivirus pLV-GFP-shGRP75RNAi (GRP75-shRNA), pLVGFP-RNAi with negative control shRNA insertion (NC-shRNA), or further rescued by GRP75-EGFP plasmid overexpression. (E) HeLa cells were transiently transfected with GRP75 constructs as listed in Figure 3A. The cell cycle distribution was determined at 48 hours post-transfection. Untransfected (Ctrl) or pEGFP plasmid (vector) transfected cells were used for comparison. Representative FACS results are shown. (B, D, F) The graphs show the percentage of living cells in the various phases of the cell cycle after corresponding treatments (A), or transfections (C, E). Data are the average results from three independent experiments. (G) Western blot analysis of endogenous GRP75 level after MKT-077 blockage or shRNA knock-down in HeLa cells. Similar results were found in Cos-7 cells (Data not shown). 

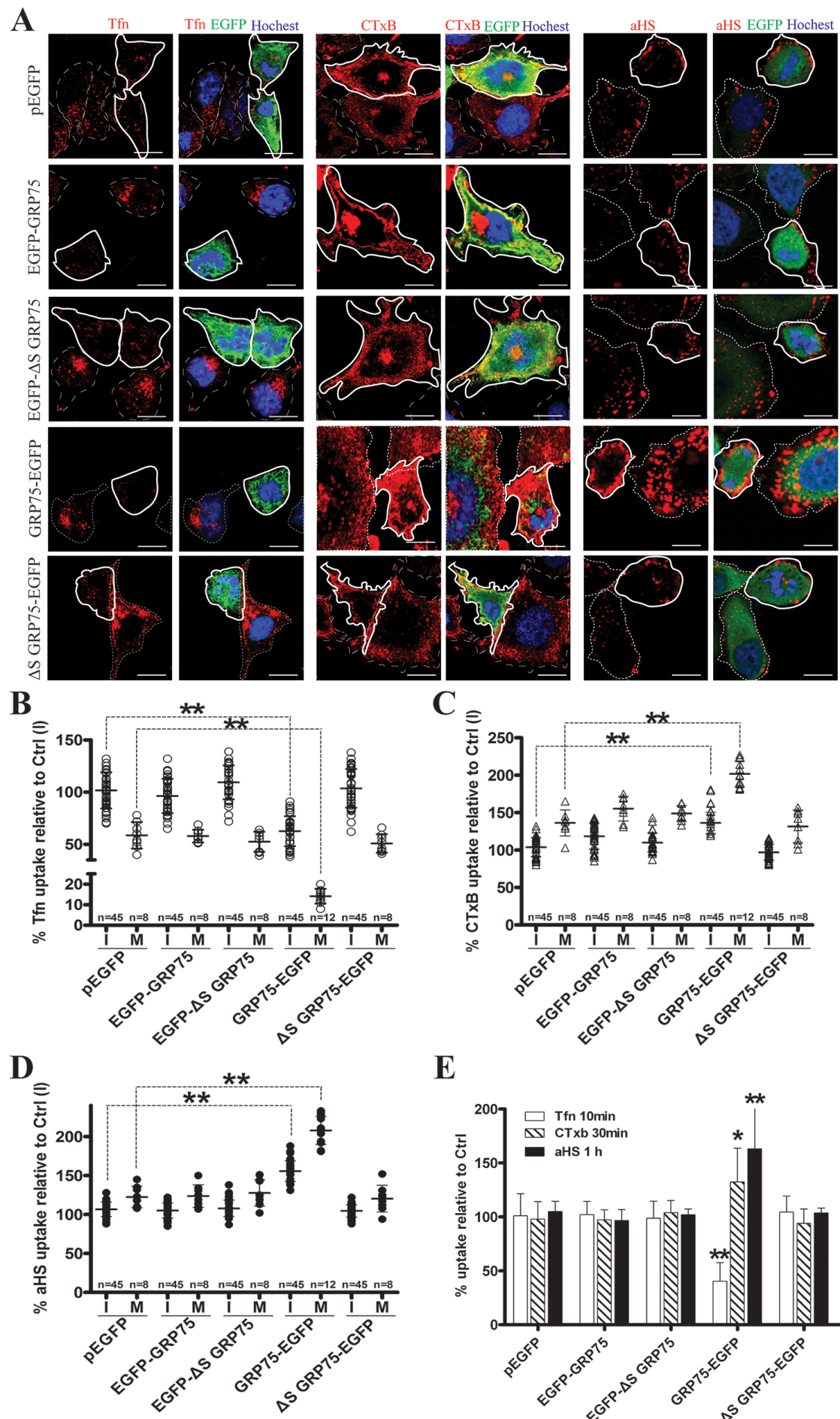

$\mathbf{E}$

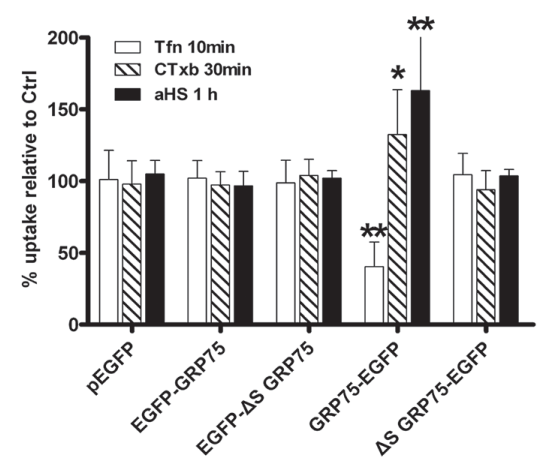

Figure 5: Mito-trafficked expression of GRP75 inhibits CME but promotes CIE. HeLa cells were transfected with GRP75 constructs as listed in Figure 3A. Cells were quickly rinsed with $\mathrm{PBS} / 0.5 \mathrm{M} \mathrm{NaCl}$, growth continued for $48 \mathrm{~h}$, then Tfn-AF647 $(25 \mu \mathrm{g} /$ $\mathrm{ml}, 15 \mathrm{~min})$, CTxB-AF647 $(10 \mu \mathrm{g} / \mathrm{ml}, 30 \mathrm{~min})$, and $\alpha \mathrm{HS}-\mathrm{AF} 647$ complex $(1: 20,1 \mathrm{~h})$ were respectively added at $37^{\circ} \mathrm{C}$. Cell uptake was determined by confocal imaging analysis, and representative images are shown in (A). Scale bar: 20 um. (B, C, D) Scatterplots depict the uptake variability of indicated transfections in single cell populations. Uptake levels in the M (polygons with bold solid line) or I phase (polygons with thin dotted line) cells are quantified as described in 'Materials and methods', and the uptake of untransfected cells in the I phase, Ctrl (I), was set as $100 \%$ for comparison. At least 45 cells were counted for the I phase and $\geq 8$ cells were counted for the M phase for each transfection. (E) The uptake levels of EGFP-positive cells collected from transfected populations were analyzed and quantified by FACS. 10,000 cells were counted per transfection in each experiment. Statistically significant differences compared with untransfected cells are shown: $* * P<0.01, * P<0.05$. 
GRP75 has been identified as an important oncotarget, and its inhibition could dramatically improve cancer patients' responses to chemotherapies [43, 44]. Recent advances showed that GRP75 has functions that are distinct from those of the related heat shock proteins. It can be actively translocated to other cellular locations and therefore assume novel functions that control intracellular trafficking, modify the immune response, and regulate viral release $[31,32,45,46]$. We previously demonstrated the presence of GRP75 at the HeLa cell surface as well as its enrichment in endocytic vesicles. Importantly, we provided evidence for a functional role of GRP75 in HSPG ligand-induced vesicular transport of nanoparticle payloads ( $\mathrm{scFv}-\alpha \mathrm{HSM}, \mathrm{scFv}-\alpha \mathrm{HSF}$, and TatDNA complexes) through Cdc42-dependent, membrane raft endocytosis [31]. More recently, we demonstrated that the uptake of the HSPG-dependent macromolecular complex occurs through the CIE pathway, which is regulated by upstream GRP75 in HeLa cells. This endocytosis regulation is largely mediated by GRP75
A
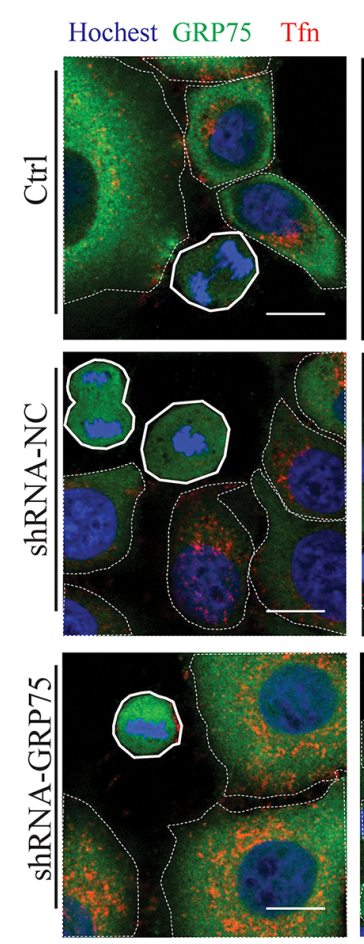

$\mathbf{E}$
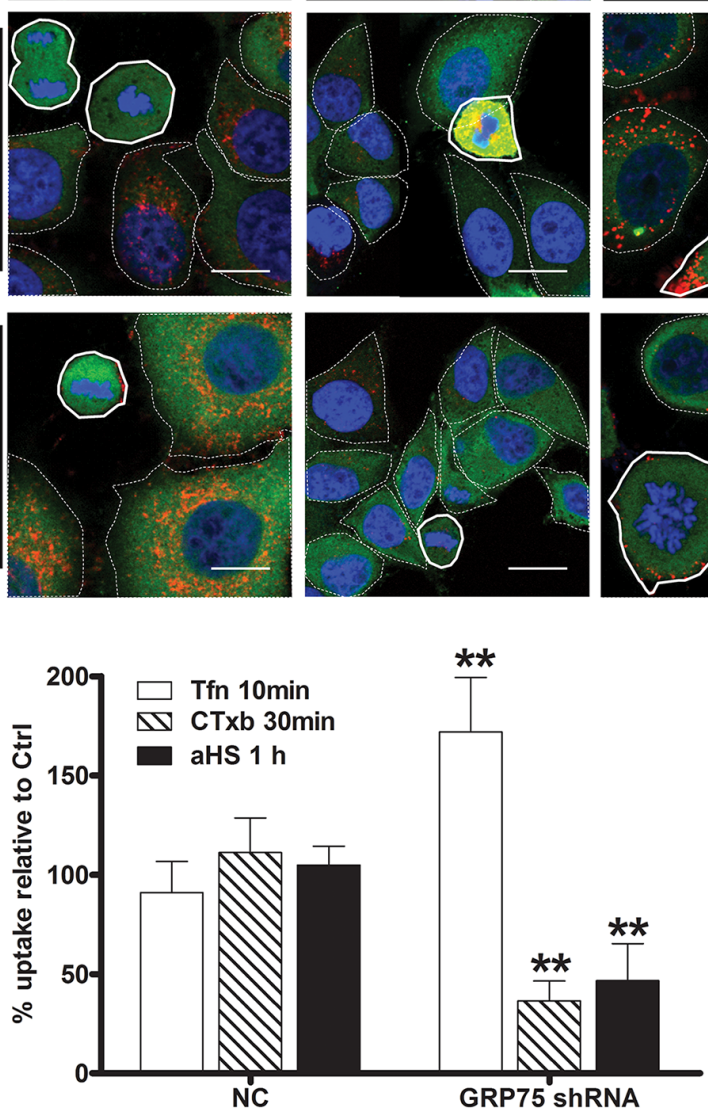

B
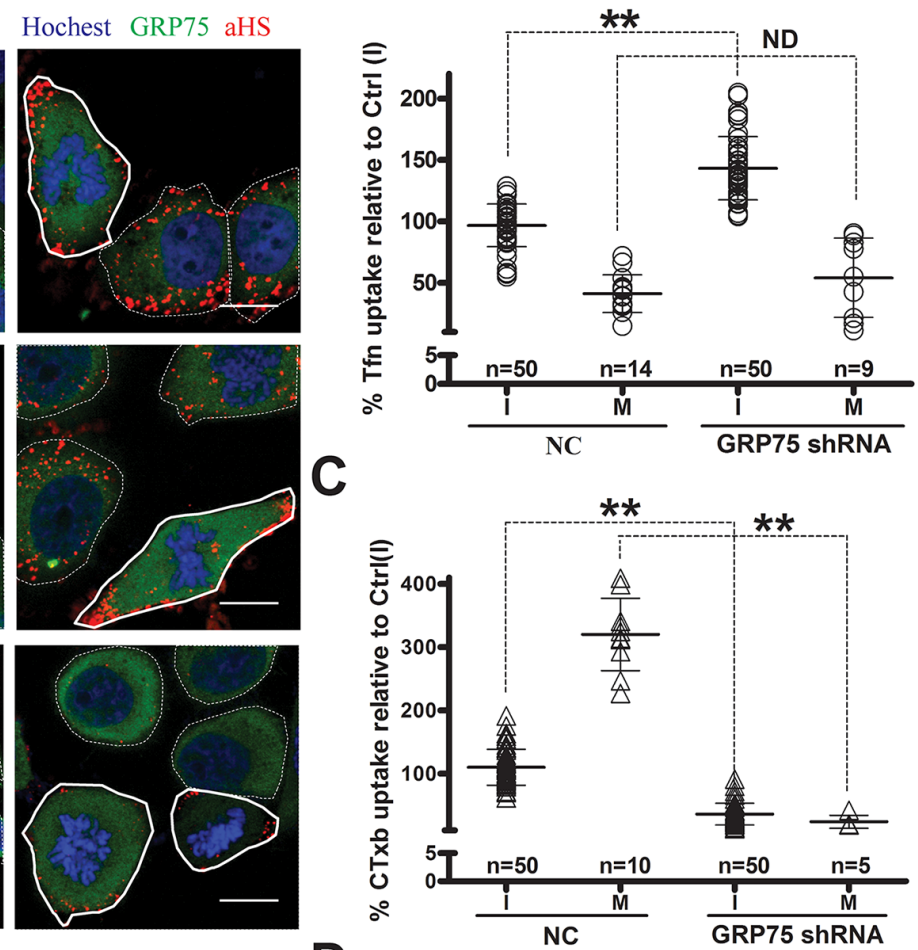

D

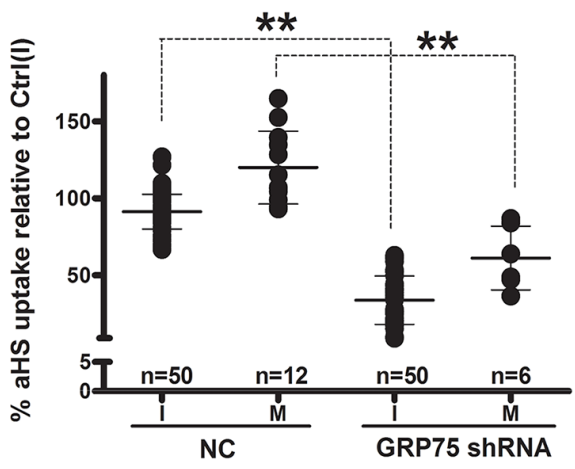

Figure 6: GRP75 knock-down promotes CME but inhibits CIE. The uptake levels of Tfn-AF647, CTxB-AF647, and andaHSAF647 complexes in GRP75-shRNA stably transduced HeLa cells were determined by confocal imaging analysis, and representative images are shown in (A). Scale bar: $20 \mathrm{um}$. Scatterplots depict the uptake variability of indicated ligands, and the uptake levels in the M (polygons with bold solid line) or I phase (polygons with thin dotted line) cells are respectively quantified in (B), (C) and (D) with comparison to that of untransfected cells in the I phase as Ctrl (I). At least 50 cells were counted for the I phase and $\geq 5$ cells were counted for the M phase for each transfection. (E) The uptake levels of EGFP-positive shRNA cell populations were analyzed and quantified by FACS. 10,000 cells were counted per sample in each experiment. Statistically significant differences compared with negative control cells (NC-shRNA) are shown: $* * P<0.01$, ND: no difference. 
in the mitochondria and is essentially determined by its ATPase domain. Overexpression of GRP75 or its ATPaseD in mitochondria stimulates RhoA and Cdc42 concurrent activation and enhances the formation of stress fibers and filopodia, collectively resulting in the promotion of CIE but the inhibition of CME [32]. In the present study, we further demonstrated that GRP75 is highly expressed in the mitochondrial fraction of mitotic HeLa and Cos-7 cells. This mitochondria-trafficked GRP75 expression, not only significantly arrests cancer cells in the cell cycle M-phase, but also promotes CIE and simultaneously inhibits CME primarily in this arrested M-phase. Therefore, we claim that the GRP75 moonlighting function is a cell cycle controller and endocytosis regulator in cancer cells. More importantly, this moonlighting function of GRP75 can be utilized to enhance the CME of nanomicrospheres sized from $40 \mathrm{~nm}$ to $100 \mathrm{~nm}$ through the GRP75 targeting/ inhibition-induced G1-phase retention effect.
A
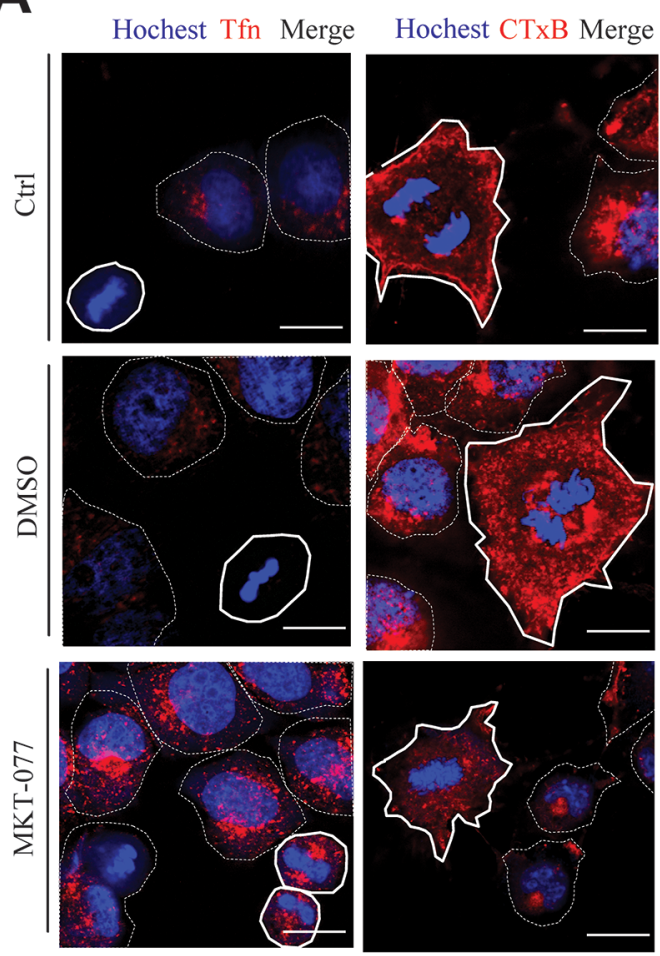

$\mathbf{E}$

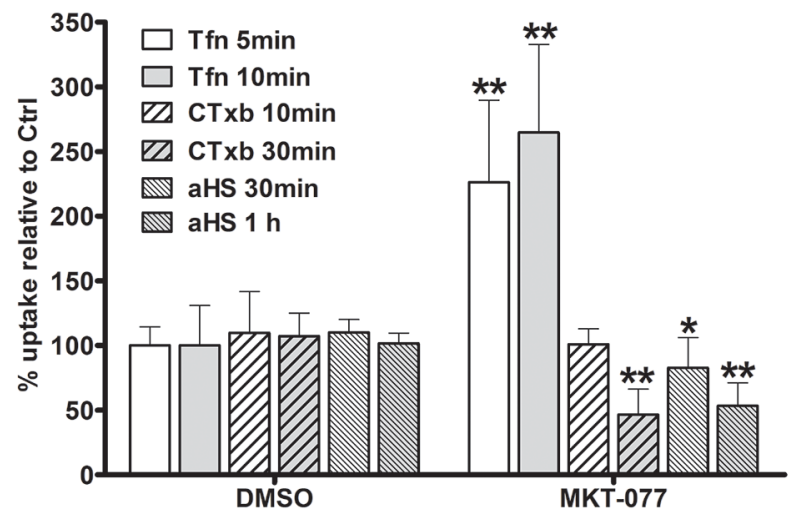

B
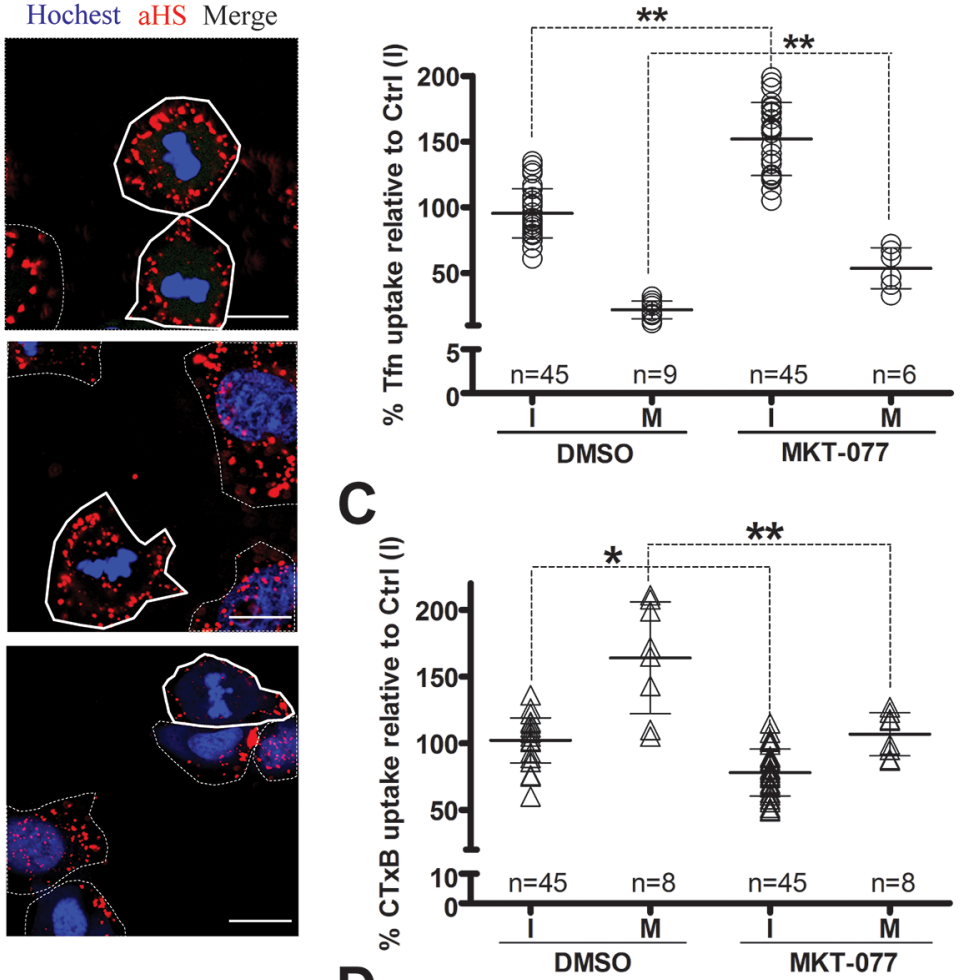

D

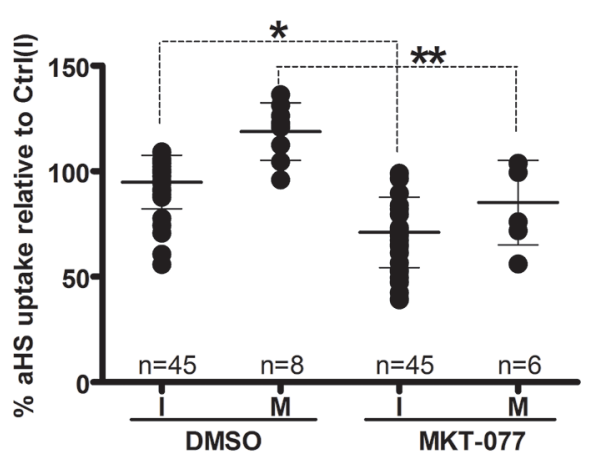

Figure 7: GRP75 targeting by MKT-077 promotes CME but inhibits CIE. HeLa cells were treated with concentration-increased MKT-077 (5, 10, 20, and 40uM) for 24 hours, and then incubated respectively with Tfn-AF647, CTxB-AF647, and $\alpha$ HS-AF647 complexes for uptake measurement as described above. Representative confocal images are shown in (A). Scale bar: 20 um. Scatterplots depict the uptake variability in $\mathrm{M}$ (polygons with bold solid line) or I phase (polygons with thin dotted line) cells, and the uptake levels compared to that of untreated cells in the I phase (Ctrl(I)) are summarized in (B), (C) and (D). At least 45 cells were counted for the I phase and $\geq 6$ cells were counted for the M phase for each treatment. (E) Ligands uptake in MKT-077 treated cells were determined by flow cytometry analysis, and the uptake levels are quantified in (E). 10,000 cells were counted per sample in each experiment. Statistically significant differences compared to untreated cells (Ctrl) are shown: $* * P<0.01, * P<0.05$. 
Different from the prevailing dogma that endocytosis is shut down during cell division, our present data showed that $\mathrm{CME}$ was markedly reduced but not completely halted in the cell cycle M-phase (Figures 1A, 1B, 1E). In mitotic cells, we detected decreased expression of clathrin in the total lysate and reduced CCV dissociation factor HSC70 in the membrane fractions, which sharply contrasts with the fold-increased total TfnR and decreased membrane-
A

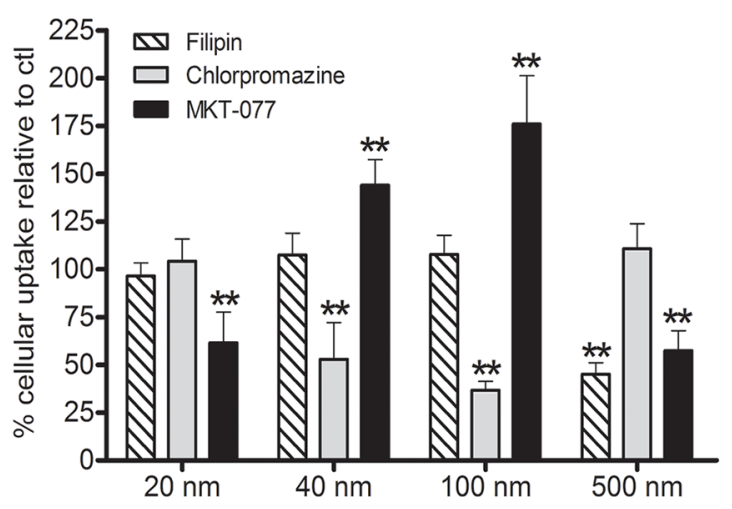

C

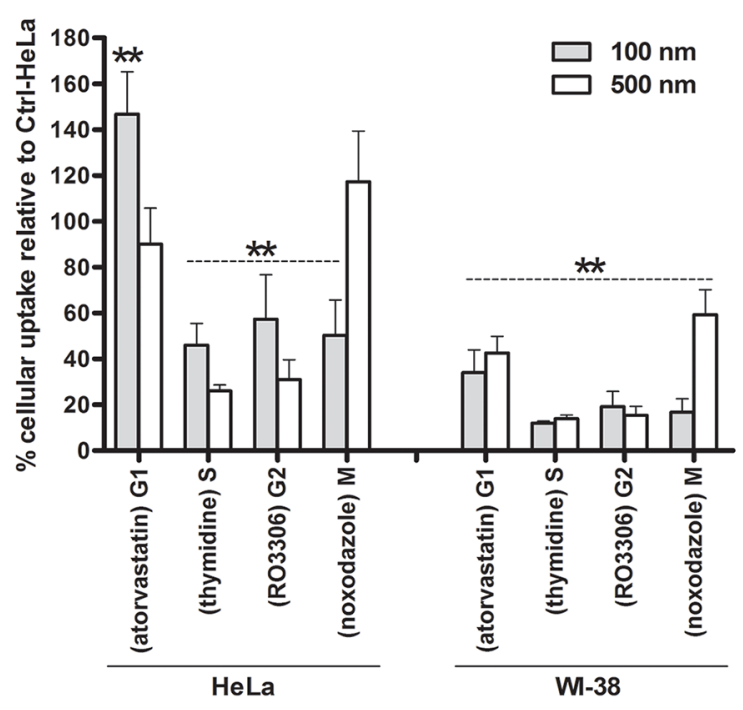

B
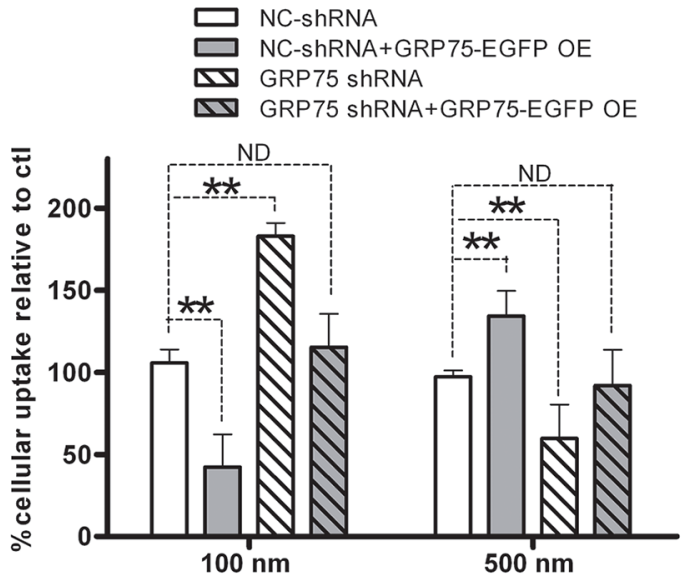

D

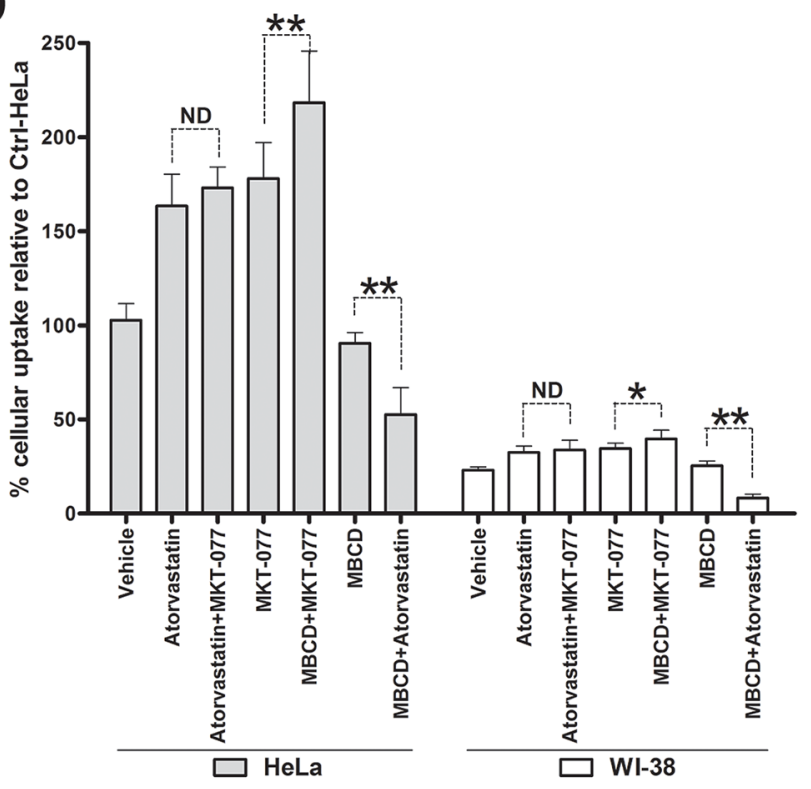

Figure 8: GRP75 targeting by MKT-077 enhances G1-phase-privileged uptake of $100 \mathrm{~nm}$ nanomicrospheres. (A) Effect of CME, CvME, and GRP75 inhibitions on the uptake of size-defined nanomicrospheres. HeLa cells were incubated respectively with filipin $(5 \mu \mathrm{g} / \mathrm{ml})$, chlorpromazine $(10 \mu \mathrm{g} / \mathrm{ml})$, or with MKT-077 $(40 \mathrm{uM})$ in serum-free medium for $24 \mathrm{~h}$. Subsequently, different sizes of fluorescent microspheres $(1: 300, \mathrm{v} / \mathrm{v})$ were added and incubated for $12 \mathrm{~h}$ in the presence of inhibitors. The uptakes of microspheres in cells were determined by flow cytometry analysis. The fluorescent intensity of nanoparticles in DMSO treated cells (Ctrl) was set as $100 \%$. (B) Effect of GRP75 knock-down and overexpression on the uptake of nanomicrospheres. GRP75-shRNA stably transduced HeLa cells (GRP75-shRNA) were transfected with the wtGRP75 plasmid for overexpression (GRP75-OE) for 12h. After extensive washing and continued growth for $18 \mathrm{~h}, 100 \mathrm{~nm}$ or $500 \mathrm{~m}$ fluorescent microspheres (1:300) were added to the cells for $12 \mathrm{~h}$ incubation and processed for flow cytometry analysis. The fluorescent intensity in cells was compared to that of the negative control (NC-shRNA). (C) Effect of arrested cell cycle phases on the uptake of nanomicrospheres. HeLa and WI-38 cells were synchronized at different cell cycle phases as described above. Fluorescent microspheres of 100 and $500 \mathrm{~nm}$ sizes were respectively added (1:300) and incubated for $12 \mathrm{~h}$ in the presence of chemical inducers. The uptakes of microspheres were determined by flow cytometry and intracellular the fluorescent intensity of untreated HeLa cells was set as $100 \%$ (Ctrl-HeLa). (D) Effect of MKT-077 combined with atorvastatin or MBCD on the uptake of $100 \mathrm{~nm}$ fluorescent microspheres. HeLa and WI-38 cells were respectively incubated with the mixtures of MKT-077 and atorvastatin, or MKT-077 and MBCD, or MBCD and atorvastatin. The uptakes of nanomicrosphere (1:300) in single or combined treated cells were determined by flow cytometry and compared to that of untreated HeLa cells (Ctrl-HeLa). ${ }^{*} 0.01<P<0.05,{ }^{* *} P<0.01$, ND: no difference. 
resident TfnR (Figure 2B). The distinct distribution of these endocytosis components during the cell cycle suggests that strong reduction of the Tfn uptake observed in the M-phase is not only due to the decreased CME but also the attenuated $\mathrm{TfnR}$ recycled from the cell surface, which supports the recent consensus that CME is inhibited during mitosis $[33,34,36]$. Although it is hard to explain why caveolin-1 expression between membrane-fractions and the total lysate presents a contrary distribution in the M-phase (Figure 2B), the continous even up-regulated uptake of the CvME marker CTxb in mitotic cells (Figures $1 \mathrm{~A}, 1 \mathrm{C}, 1 \mathrm{~F})$ indicates that $\mathrm{CIE}$ activity may be required for plasma membrane remodeling when cells undergo division. This is somehow similar to the previous report that EGF internalization in mitotic cells occurs much slower at the early stage of mitosis but the total amount of internalized EGF approaches that seen in interphase cells [47]. However, we observed that CME dominated in the I-phase versus up-regulated CIE in the M-phase which reveals that there is an endocytosis balance or shift during the cell cycle.

Although membrane-associated GRP75 is dispersed during the cell cycle, mitochondrion-resident GRP75 is highly enriched during G2/M-phases (Figure 2B). The cell cycle specific expression and differential mitochondria localization together with its highly expression-induced mitotic phase arrest (Figure 4), collectively indicate the role of GRP75 in cell cycle control. However, the underlying mechanism whereby GRP75 controls cell cycle distribution was not the focus of our present study. Work from other labs contributes a lot on this aspect. In MEK/ERK-activated cancer cells and hematopoietic stem cells, GRP75 depletion/targeting-induced cell cycle arrest was accompanied by increased expression of cyclindependent kinase inhibitor $\mathrm{p} 21^{\mathrm{CIP} 1}$, tumor suppressor $\mathrm{p} 53$, and decreased expression of cyclin-dependent kinase inhibitor $\mathrm{p} 27^{\mathrm{KIP} 1}$, S-phase transcription factor E2F-1, and $\mathrm{Rb}$ phosphorylation, indicating that GRP75 may regulate the cell cycle via cyclin-dependent kinas/TP53/ $\mathrm{Rb}$ signaling [23, 26, 28, 30, 48]. Notably, another study on cell cycle arrest experiments found that HSP70 specific inhibitor PES-Cl treatment could effectively inhibit cyclin $\mathrm{B}$ degradation and APC/C (anaphase promoting complex/ cyclosome) activity, which always resulted in G2/M arrest in cancer cells [29]. As several HSP70 family members are required for $\mathrm{CDK} 1 /$ cyclin $\mathrm{B}$ complex assembly, whether GRP75 is also involved in this complex activity is worthy of future research.

Mitochondria are highly dynamic organelles which always transport to special cellular regions to meet energy needs. Because GRP75 is indispensable to mitochondrial morphology and bioenergetic maintenance, from the perspective that endocytosis and cell division are energy-dependent cellular behaviors, GRP75 localized in mitochondria should be essential to both processes. We previously found that vesicle-enriched endogenous GRP75 also appears on the cell surface and exogenous GRP75 trafficking-expressed in mitochondria could up-regulate CIE $[31,32]$. In this study, we further strengthened this aspect by showing the contributions of mitochondriatrafficked GRP75 on cell cycle M-phase accumulation and endocytosis shift (Figures 4, 5). Such subcellular localization-determined moonlighting function was also reported on other endocytosis regulators and chaperone proteins: (1) Cdc42 GTPase is the master regulator of clathrin- and dynamin-independent endocytosis. Silencing of its specific GEF Intersectin 2 can attenuate Cdc42 activation but also disrupt the correct orientation of the mitotic spindle during epithelial morphogenesis [49]. (2) A sub-fraction of cytoplasmic chaperone HSP70 was shown to cluster in lipid raft areas, which enhances CIE through oligomerisation and clustering on the melanoma cell surface [50]. (3) Significant amounts of endoplasmic reticulum resident chaperone calreticulin were found in physical association with MHC I molecules on the activated $\mathrm{T}$ cell surface [51]. (4) Another endoplasmic reticulum chaperone GRP78 was found to act as a binding receptor for caveolae-dependent endocytosis of dentin matrix proteins [52]. In light of the dynamic transport of mitochondria to the cell membrane, these observations together with our present findings suggest that M-phaseenriched mito-GRP75 may maintain the stability of lipid raft-associated membrane flow structures, which promotes CIE but inhibits CME in mitotic cancer cells.

Nanoparticles are considered a primary vehicle for targeted therapies because they can pass biological barriers and enter and distribute within tissue cells by energy-dependent pathways. The big problem is that the uptake of nanoparticles by cells is not only affected by their properties, such as size and surface charge, but also influenced by the cell cycle phase. Some studies have shown that the cellular uptake efficiency of nanoparticles during the cell cycle is ranked as follows: $\mathrm{G} 2 / \mathrm{M}>\mathrm{S}>$ $\mathrm{G} 0 / \mathrm{G} 1[40,41,53]$. Utilizing this $\mathrm{G} 2 / \mathrm{M}$ phase retention effect, researchers elevated the uptake of nanoparticles in tumors by different chemotherapeutic pretreatments $[54,55]$. Despite gaining intracellular delivery of nanoparticles, the final effects of tumor suppression in vivo are ambiguous. One reason for this is that at different stages of the cell cycle, the dominant endocytosis pathway can vary leading to the differential uptake of certain particles. Another reason is that tumor growth is characterized by an exponential proliferation phase and a second non-proliferating phase, in which cancer cells are always dormant in the cell cycle G0/G1 phase due to nutrient deprivation or hypoxia. Since CME is suppressed during mitosis but dominant at the interphase of cell cycle (Figure 1), and cancer cell internalize $40 \mathrm{~nm}$ to $100 \mathrm{~nm}$ nanomicrospheres via the CME pathway (Figure 8A), one solution is the use of combined therapies, in which one component accumulates the cell cycle at the G1 phase, and another delivers the therapeutic drugs through CME. 
As MKT-077 is a cancer cell-selective small molecule inhibitor, our present initiative based on the utilization of the GRP75 targeting-induced G1-phase-privileged CME route is a simple approach to enhance the delivery efficiency of such kind of nanoparticles. Although we only have promising data on improving certain sizes of nanomicrospheres delivery (Figure 8D), more work is needed to consummate this moonlight function targeting approach. This should at least include checking the delivery efficiency of ligands (e.g. $\alpha \mathrm{HS}$ Ao4B08, Tfn, TAT)-modified active targeting nanomicrospheres in vitro and in vivo. Such experimental work has begun in our lab.

\section{MATERIALS AND METHODS}

\section{Cell culture, nanoparticles, antibodies, and reagents}

HeLa, Cos-7, WI-38, and 293T cell lines obtained from the Type Culture Collection of Chinese Academy of Sciences (P.R. China), were maintained in Dulbecco's modified eagle's medium (DMEM) containing 10\% (v/v) fetal bovine serum. Red fluorescent (580/605) labeled, carboxylate-modified microspheres were obtained from Thermo Fisher without further modification. The sizes of fluorescent nanoparticles were 20, 40, 100, 500, and $2000 \mathrm{~nm}$ in diameter (F8786, F8793, F8801, F8812, and F8826, respectively). The mouse anti-GRP75 antibody (Ab) (SC-133137), anti-Hsc70 Ab (sc-7298), antiTfnR Ab (sc-32272), anti-clathrin Ab (sc-12734), anticaveolin-1 Ab (sc-53564), and anti-caveolin-2 Ab (sc7942) were obtained from Santa Cruz. The rabbit anti-GFP Ab (D110008), anti-B-actin Ab (sc-7210), anti- voltagedependent anion channel 1(VDAC) Ab (D151112), thymidine (A500943), nocodazole (A606391), colcomid (A600322), and mitochondria/cytoplasm isolation kits (C500049, C500051) were obtained from Sangon Biotech. The mitochondria-selective probe mitoTracker®Red (M7512), Tfn-alexa fluor (AF) 647 (T-23366), CTxBAF647 (C-34778), goat anti-mouse Ab-AF488 (A-11001), anti-mouse IgG-AF647 (A32728), anti-rabbit Ab-AF488 (A-11070), and Lipofectamine 3000 were obtained from Life technologies. The mouse anti-VSV Ab P5D4 (V5507), MKT-077 (M5449), atorvastatin (PZ0001), RO3306 (SML0569), Hochest33342, propidium Iodide (P4170), RNAseA (R6513), polybrene (H9268), and puromycin (P7255) were obtained from Sigma.

\section{Plasmid constructs for knock-down and overexpression}

EGFP N-/C-terminal fused GRP75 plasmids with/ without mitochondrial targeting signal peptide (mTP) (wtGRP75-EGFP, $\triangle$ SGRP75-EGFP, EGFP-wtGRP75, and EGFP- $\triangle$ SGRP75) were as previously constructed $[32,56]$. For gene overexpression, recombinant GRP75 plasmids were transient transfected into $60-70 \%$ confluent cells by Lipofectamine $\AA 3000$ according to the manufacturer's instructions. The GFP-tagged pLV-RNAi vector system was obtained from Biosettia for long-term gene silencing. Three independent GRP75-targeting shRNA constructs were generated by ligation of annealed oligonucleotides, which target different regions of human GRP75 mRNA (shRNA\#1: GCAGTTGTTGGTATTGATT, shRNA\#2: GCTCATGGGAAATTGTATT, and shRNA\#3: GCCCTATCTTACAATGGAT), into the pLV-H1EF1 $\alpha$-GFP-Puro plasmid (SORT-B29), respectively. For lentivirus production, 293T cells were co-transfected by recombinant pLV-RNAi plasmids together with GagPol, Rev, and VSV-G packaging plasmids, as described in their manual. Viral supernatants were collected after $72 \mathrm{~h}$ and mixed with polybrene $(4 \mathrm{ug} / \mathrm{ml})$ before use. Viral titers were determined by scoring cells expressing green fluorescent protein (EGFP). The optimal puromycin concentration $(3 \mu \mathrm{g} / \mathrm{ml})$ was used to select stably transduced cell lines. Specific overexpression and knockdown of the GRP75 protein were confirmed by Western blotting.

\section{Culture synchronization and cell cycle analysis}

Synchronizing cells from different phases of the cell cycle was performed by the protocol previously described [57]. Briefly, cells were treated with serumfree/limited medium (G0/G1 phase), or treated with for HMG-CoA reductase inhibitor atorvastatin ( $\mathrm{G} 1$ phase), or treated with double thymidine block procedure (S phase), or treated with CDK1 inhibitor RO3306 (G2 phase), or treated with nocodazole/colcomid (M phase) for indicated times as described in the legend of Supplementary Figure 1. To assess the cell cycle distribution, all the above cells were collected and fixed in $70 \%$ ethanol overnight. After removal of the ethanol, samples were washed three times with PBS, and then incubated with RNase A at $4^{\circ} \mathrm{C}$ for 30 min. Next, samples were stained with propidium iodide $(50 \mu \mathrm{g} / \mathrm{ml})$ and evaluated by a flow cytometer. To assess the cell cycle distribution after GRP75 knock-down or overexpression, transfected cells were sorted by FACS Calibur (BD) with a gate that separated the EGFP-positive cells for cell cycle analysis as described above. The subsequent analysis was conducted by FlowJo software.

\section{Uptake measurement by flow cytometry analysis}

To measure the uptakes, transfected or synchronized cells was first washed twice with serum-free medium to reduce paracrine effects. Only attached live cells were exposed to check the binding and uptake of Tfn-AF647 $(25 \mu \mathrm{g} / \mathrm{ml}), \quad$ CTxB-AF647 $(10 \mu \mathrm{g} / \mathrm{ml}), \quad \alpha \mathrm{HS}-\mathrm{AF} 647$ complex (1:20), and fluorescent nanospheres $(1: 300)$ in incomplete medium as previously described [31, 32]. Binding incubation with these ligands was performed 
for $30 \mathrm{~min}$ on ice. Cells were then washed twice with PBS and immediately analyzed on the FACSCalibur instrument integrated with Cell-Quest software. For uptake measurement, cells were incubated with TfnAF647 (15min), CTxB-AF647 (30min), aHS-AF647 complex $(1 \mathrm{~h})$, and fluorescent nanospheres for indicated times at $37{ }^{\circ} \mathrm{C}$, and then $0.4 \%(\mathrm{w} / \mathrm{v})$ Trypan Blue in PBS was added to quench cell surface-associated fluorescence. Samples were washed twice with $\mathrm{PBS} / 0.5 \mathrm{M} \mathrm{NaCl}$, harvested with trypsin/EDTA, resuspended with PBS, and intracellular fluorescence was immediately detected using the FACSCaliber flow cytometer.

To compare the uptake of a synchronized culture to that of a non-synchronized one, care was taken to ensure that a similar number of cells were prepared for fluorescent ligands/nanoparticles uptake. In addition, prior to addition of fluorescent ligands/particles, various inhibiting conditions were achieved in cells via $24 \mathrm{~h}$ incubation with serum-free media containing chlorpromazine $(10 \mathrm{mg} /$ $\mathrm{mL})$, filipin $(5 \mathrm{mg} / \mathrm{mL})$, atorvastatin $(1 \mathrm{mg} / \mathrm{mL})$, methylB-cyclodextrin $(10 \mathrm{mM})$, or MKT-077 at a concentration as described in the text. Stock solutions of these drugs were made in DMSO, diluted in PBS, and the final concentration of DMSO was less than $0.4 \%$.

\section{Uptake measurement by confocal imaging analysis}

Cells in chamber slides were first washed twice with serum-free medium, and then incubated with fluorescent labeled ligands/nanoparticles as described above at $37^{\circ} \mathrm{C}$. After rinsing twice with $\mathrm{PBS} / 0.5 \mathrm{M} \mathrm{NaCl}$ to remove cell surface-associated ligands, cells were fixed in $3.7 \%(\mathrm{w} / \mathrm{v})$ paraformaldehyde for $10 \mathrm{~min}$. Honest33342 (1:1000) nuclear staining was performed after cell permeabilization with $0.1 \%$ Triton X-100. The cells were mounted, observed, and images were acquired using an Olympus FV 1000 laser scanning confocal microscope equipped with $63 \times / 1.4$ N.A. and $100 \times / 1.44$ N.A. oil immersion lens. Sixteen-bit z-series of confocal sections (step size $=$ $0.42 \mu \mathrm{m}$ for $63 \times$ objective and $0.29 \mu \mathrm{m}$ for $100 \times$ objective) were acquired in the photon-counting mode, and these acquisition parameters were kept identical across all samples. For image presentation, eight-bit maximal projections of the z-series were created using ImageJ software, and the brightness was adjusted across the entire image using Volocity software. The quantification details of these fluorescent ligands/particles were previously described[32].

For labeling of mitochondria and immunostaining of EGFP-fused proteins, transfected cells were incubated with $300 \mathrm{nM}$ mitoTracker at $37^{\circ} \mathrm{C}$ for $40 \mathrm{~min}$, then washed twice with $\mathrm{PBS} / 0.5 \mathrm{M} \mathrm{NaCl}$, fixed in $3.7 \%$ formaldehyde for $10 \mathrm{~min}$ at room temperature, penetrated with $0.1 \%$ TritonX-100 for $5 \mathrm{~min}$ at room temperature, sealed with $10 \%$ goat serum, and immunostained with anti-GFP antibody (1:1000), followed by staining with goat antirabbit Ab-AF488 (1:1000), and then cells were mounted for confocal imaging.

\section{Cell fractionation and western blotting}

The cytosol, membrane, and mitochondrial fractions of synchronized cells were extracted by the differential centrifugation method as described in the kit description. The protein concentration of the samples in lysis buffer (50 mM Tris- $\mathrm{HCl}, \mathrm{pH} 8,150 \mathrm{mM} \mathrm{NaCl}, 1 \% \mathrm{NP}-40,0.5 \%$ sodium deoxycholate, and $0.1 \%$ SDS) was measured using the BCA assay, resolved by SDS-PAGE, blotted onto PVDF membranes, and then analyzed with different Abs diluted as follows: rabbit anti-GFP Ab (1:2000), antiB-actin Ab (1:1000), anti-VDAC Ab (1:2000), mouse anti-GRP75 Ab (1:1000), anti-Hsc70 Ab (1:500), anticaveolin-1 Ab (1:500), anti-caveolin-2 Ab (1:500), antiTfnR Ab (1:500), and anti-clathrin Ab (1:500).

\section{Bioinformatics prediction}

Online programs of WOLF PSORT (http://genscript/ wolf-psort.html), TargetP 1.1 (http://cbs.dtu.dk/services/ TargetP), and Mitoptot II (https://ihg.gsf.de/ihg/mitoprot. html), all three based on predicting N-terminal mTP and calculating the probability of proteins imported into the mitochondria, were used to predict the subcellular localization of EGFP-fused GRP75 proteins. Online database Cyclebase 3.0 [58], a multi-organism database on cell-cycle regulation and phenotypes, inside which mRNA and protein expression information based on high-content screens and model organism data integrated from genomewide, cell-cycle-related experiments, was used to predict the expression level of GRP75 in sub-phases of the cell cycle.

\section{Statistical analyses}

Confocal microscopy, flow cytometry, and Western blotting data were derived from at least three independent experiments. All of the data obtained from the experiments were analyzed and are presented as the mean \pm SD. For two-sample comparisons against the controls, unpaired Student's t-tests were used unless otherwise noted. One-way analysis of variance with Dunnett's multiple comparison was used to evaluate the statistical significance of at least three groups of samples. Graphs were created using GraphPad Prism 5 software.

\section{Abbreviations}

Ab, antibody; AF647, alexa fluor dye 647; $\alpha \mathrm{HS}$, anti-heparin sulfate single chain antibody; CME, clathrin-mediated endocytosis; CIE, clathrin-independent endocytosis; CvME, caveolae-mediated endocytosis; CTXB, cholera toxin B subunit; EGFP, enhanced green 
fluorescent protein; GRP, glucose-regulated protein; HSPG, heparan sulfate proteoglycan; mTP, mitochondrialtargeting signal peptide; $\Delta \mathrm{S}$, without mitochondrialtargeting signal peptides; Tfn, transferrin; TfnR, transferrin receptor;

\section{Author contributions}

Zhang Si-he initiated the idea and working approach, supervised the research, and wrote the manuscript. Gao Zhi-Hui, Niu Xiu-Ran, and Zhang Qing performed most of the experiments, participated in discussions, and data organization. Mattias Belting provided technical supports and bioinformatics analysis. Other authors performed some of the experiments.

\section{ACKNOWLEDGMENTS}

We apologize to any authors whose work we may have omitted. We are grateful to Prof. Toin H. van Kuppevelt (Nijmegen Centre for Molecular Life Sciences) for kindly supplying anti-HS Ab AO4B08. Thanks to Dr. Edward C. Mignot, Shandong University, for linguistic advice.

\section{CONFLICTS OF INTEREST}

The authors declare no conflicts of interest.

\section{FINANCIAL SUPPORT}

This work was supported by the National Natural Science Found of China (No. 81373318, 30700829), Natural Science Found of Tianjin (No. 16JCYBJC23900), and Open Fund of State Key Laboratory of Medicinal Chemical Biology (Nankai University) (No. 20130575).

\section{REFERENCES}

1. Jeffery CJ. An introduction to protein moonlighting. Biochem Soc Trans. 2014; 42:1679-83.

2. Jeffery CJ. Moonlighting proteins. Trends Biochem Sci. 1999; 24:8-11.

3. Mani M, Chen C, Amblee V, Liu H, Mathur T, Zwicke G, Zabad S, Patel B, Thakkar J, Jeffery CJ. MoonProt: a database for proteins that are known to moonlight. Nucleic Acids Res. 2015; 43:D277-82.

4. Hernández S, Ferragut G, Amela I, Perez-Pons J, Piñol J, Mozo-Villarias A, Cedano J, Querol E. MultitaskProtDB: a database of multitasking proteins. Nucleic Acids Res. 2014; 42:D517-20.

5. Chapple CE, Robisson B, Spinelli L, Guien C, Becker E, Brun C. Extreme multifunctional proteins identified from a human protein interaction network. Nat Commun. 2015; 6:7412.
6. Henderson B, Martin AC. Protein moonlighting: a new factor in biology and medicine. Biochem Soc Trans. 2014; 42:1671-78.

7. Min KW, Lee SH, Baek SJ. Moonlighting proteins in cancer. Cancer Lett. 2016; 370:108-16.

8. Zanzoni A, Chapple CE, Brun C. Relationships between predicted moonlighting proteins, human diseases, and comorbidities from a network perspective. Front Physiol. 2015; 6:171.

9. Henderson B, Allan E, Coates AR. Stress wars: the direct role of host and bacterial molecular chaperones in bacterial infection. Infect Immun. 2006; 74:3693-706.

10. Candela M, Bergmann S, Vici M, Vitali B, Turroni S, Eikmanns BJ, Hammerschmidt S, Brigidi P. Binding of human plasminogen to Bifidobacterium. J Bacteriol. 2007; 189:5929-36.

11. Knaust A, Weber MV, Hammerschmidt S, Bergmann S, Frosch M, Kurzai O. Cytosolic proteins contribute to surface plasminogen recruitment of Neisseria meningitidis. J Bacteriol. 2007; 189:3246-55.

12. Xolalpa W, Vallecillo AJ, Lara M, Mendoza-Hernandez G, Comini M, Spallek R, Singh M, Espitia C. Identification of novel bacterial plasminogen-binding proteins in the human pathogen Mycobacterium tuberculosis. Proteomics. 2007; 7:3332-41.

13. Long KH, Gomez FJ, Morris RE, Newman SL. Identification of heat shock protein 60 as the ligand on Histoplasma capsulatum that mediates binding to CD18 receptors on human macrophages. J Immunol. 2003; 170:487-94.

14. Pantzar $\mathrm{M}$, Teneberg $\mathrm{S}$, Lagergård $\mathrm{T}$. Binding of Haemophilus ducreyi to carbohydrate receptors is mediated by the $58.5-\mathrm{kDa}$ GroEL heat shock protein. Microbes Infect. 2006; 8:2452-58.

15. Bergonzelli GE, Granato D, Pridmore RD, MarvinGuy LF, Donnicola D, Corthésy-Theulaz IE. GroEL of Lactobacillus johnsonii La1 (NCC 533) is cell surface associated: potential role in interactions with the host and the gastric pathogen Helicobacter pylori. Infect Immun. 2006; 74:425-34.

16. Ensgraber M, Loos M. A 66-kilodalton heat shock protein of Salmonella typhimurium is responsible for binding of the bacterium to intestinal mucus. Infect Immun. 1992; 60:3072-78.

17. Yamaguchi H, Osaki T, Kurihara N, Taguchi H, Hanawa T, Yamamoto T, Kamiya S. Heat-shock protein 60 homologue of Helicobacter pylori is associated with adhesion of $\mathrm{H}$. pylori to human gastric epithelial cells. J Med Microbiol. 1997; 46:825-31.

18. Hickey TB, Thorson LM, Speert DP, Daffé M, Stokes RW. Mycobacterium tuberculosis Cpn60.2 and DnaK are located on the bacterial surface, where Cpn60.2 facilitates efficient bacterial association with macrophages. Infect Immun. 2009; 77:3389-401. 
19. Song X, Wang X, Zhuo W, Shi H, Feng D, Sun Y, Liang Y, Fu Y, Zhou D, Luo Y. The regulatory mechanism of extracellular Hsp90 \{alpha\} on matrix metalloproteinase-2 processing and tumor angiogenesis. J Biol Chem. 2010; 285:40039-49.

20. Li W, Li Y, Guan S, Fan J, Cheng CF, Bright AM, Chinn C, Chen M, Woodley DT. Extracellular heat shock protein90alpha: linking hypoxia to skin cell motility and wound healing. EMBO J. 2007; 26:1221-33.

21. Eustace BK, Jay DG. Extracellular roles for the molecular chaperone, hsp90. Cell Cycle. 2004; 3:1098-100.

22. Eustace BK, Sakurai T, Stewart JK, Yimlamai D, Unger C, Zehetmeier C, Lain B, Torella C, Henning SW, Beste G, Scroggins BT, Neckers L, Ilag LL, Jay DG. Functional proteomic screens reveal an essential extracellular role for hsp90 alpha in cancer cell invasiveness. Nat Cell Biol. 2004; 6:507-14.

23. Starenki D, Park JI. Selective Mitochondrial Uptake of MKT-077 Can Suppress Medullary Thyroid Carcinoma Cell Survival In Vitro and In Vivo. Endocrinol Metab (Seoul). 2015; 30:593-603.

24. Bocharov AV, Vishnyakova TG, Baranova IN, Remaley AT, Patterson AP, Eggerman TL. Heat shock protein 60 is a high-affinity high-density lipoprotein binding protein. Biochem Biophys Res Commun. 2000; 277:228-35.

25. Asquith KL, Baleato RM, McLaughlin EA, Nixon B, Aitken RJ. Tyrosine phosphorylation activates surface chaperones facilitating sperm-zona recognition. J Cell Sci. 2004; 117:3645-57.

26. Hu Y, Yang L, Yang Y, Han Y, Wang Y, Liu W, Zuo J. Oncogenic role of mortalin contributes to ovarian tumorigenesis by activating the MAPK-ERK pathway. J Cell Mol Med. 2016; 20:2111-21.

27. Flachbartová Z, Kovacech B. Mortalin - a multipotent chaperone regulating cellular processes ranging from viral infection to neurodegeneration. Acta Virol. 2013; 57:3-15.

28. Starenki D, Hong SK, Lloyd RV, Park JI. Mortalin (GRP75/ HSPA9) upregulation promotes survival and proliferation of medullary thyroid carcinoma cells. Oncogene. 2015; 34:4624-34.

29. Budina-Kolomets A, Balaburski GM, Bondar A, Beeharry $\mathrm{N}$, Yen T, Murphy ME. Comparison of the activity of three different HSP70 inhibitors on apoptosis, cell cycle arrest, autophagy inhibition, and HSP90 inhibition. Cancer Biol Ther. 2014; 15:194-99.

30. Wu PK, Hong SK, Veeranki S, Karkhanis M, Starenki D, Plaza JA, Park JI. A mortalin/HSPA9-mediated switch in tumor-suppressive signaling of Raf/MEK/extracellular signal-regulated kinase. Mol Cell Biol. 2013; 33:4051-67.

31. Wittrup A, Zhang SH, Svensson KJ, Kucharzewska P, Johansson MC, Mörgelin M, Belting M. Magnetic nanoparticle-based isolation of endocytic vesicles reveals a role of the heat shock protein GRP75 in macromolecular delivery. Proc Natl Acad Sci USA. 2010; 107:13342-47.

32. Chen H, Gao Z, He C, Xiang R, van Kuppevelt TH, Belting M, Zhang S. GRP75 upregulates clathrin-independent endocytosis through actin cytoskeleton reorganization mediated by the concurrent activation of $\mathrm{Cdc} 42$ and RhoA. Exp Cell Res. 2016; 343:223-36.

33. Fürthauer M, González-Gaitán M. Endocytosis and mitosis: a two-way relationship. Cell Cycle. 2009; 8:3311-18.

34. Fielding AB, Royle SJ. Mitotic inhibition of clathrinmediated endocytosis. Cell Mol Life Sci. 2013; 70:3423-33.

35. $\mathrm{Fu} \mathrm{W}$, Jiang Q, Zhang C. Novel functions of endocytic player clathrin in mitosis. Cell Res. 2011; 21:1655-61.

36. Fielding AB, Willox AK, Okeke E, Royle SJ. Clathrinmediated endocytosis is inhibited during mitosis. Proc Natl Acad Sci USA. 2012; 109:6572-77.

37. Tacheva-Grigorova SK, Santos AJ, Boucrot E, Kirchhausen T. Clathrin-mediated endocytosis persists during unperturbed mitosis. Cell Reports. 2013; 4:659-68.

38. Brodsky FM, Sosa RT, Ybe JA, O'Halloran TJ. Unconventional Functions for Clathrin, ESCRTs, and Other Endocytic Regulators in the Cytoskeleton, Cell Cycle, Nucleus, and Beyond: Links to Human Disease. Csh Perspect Biol; 2014. p. 6.

39. Nakayama K. Regulation of cytokinesis by membrane trafficking involving small GTPases and the ESCRT machinery. Crit Rev Biochem Mol Biol. 2016; 51:1-6.

40. Abouzeid AH, Torchilin VP. The role of cell cycle in the efficiency and activity of cancer nanomedicines. Expert Opin Drug Deliv. 2013; 10:775-86.

41. Hillaireau H, Couvreur P. Nanocarriers' entry into the cell: relevance to drug delivery. Cell Mol Life Sci. 2009; 66:2873-96.

42. Davis ME, Brewster ME. Cyclodextrin-based pharmaceutics: past, present and future. Nat Rev Drug Discov. 2004; 3:1023-35.

43. Fu Y, Lee AS. Glucose regulated proteins in cancer progression, drug resistance and immunotherapy. Cancer Biol Ther. 2006; 5:741-44.

44. Deocaris CC, Lu WJ, Kaul SC, Wadhwa R. Druggability of mortalin for cancer and neuro-degenerative disorders. Curr Pharm Des. 2013; 19:418-29.

45. Kaul SC, Deocaris CC, Wadhwa R. Three faces of mortalin: a housekeeper, guardian and killer. Exp Gerontol. 2007; 42:263-74.

46. Lee AS. Glucose-regulated proteins in cancer: molecular mechanisms and therapeutic potential. Nat Rev Cancer. 2014; 14:263-76.

47. Liu L, Shi H, Chen X, Wang Z. Regulation of EGFstimulated EGF receptor endocytosis during $\mathrm{M}$ phase. Traffic. 2011; 12:201-17. 
48. Tai-Nagara I, Matsuoka S, Ariga H, Suda T. Mortalin and DJ-1 coordinately regulate hematopoietic stem cell function through the control of oxidative stress. Blood. 2014; 123:41-50.

49. Rodriguez-Fraticelli AE, Vergarajauregui S, Eastburn DJ, Datta A, Alonso MA, Mostov K, Martín-Belmonte F. The Cdc42 GEF Intersectin 2 controls mitotic spindle orientation to form the lumen during epithelial morphogenesis. J Cell Biol. 2010; 189:725-38.

50. Nimmervoll B, Chtcheglova LA, Juhasz K, Cremades N, Aprile FA, Sonnleitner A, Hinterdorfer P, Vigh L, Preiner J, Balogi Z. Cell surface localised Hsp70 is a cancer specific regulator of clathrin-independent endocytosis. FEBS Lett. 2015; 589:2747-53.

51. Raghavan M, Wijeyesakere SJ, Peters LR, Del Cid N. Calreticulin in the immune system: ins and outs. Trends Immunol. 2013; 34:13-21.

52. Ravindran S, Narayanan K, Eapen AS, Hao J, Ramachandran A, Blond S, George A. Endoplasmic reticulum chaperone protein GRP-78 mediates endocytosis of dentin matrix protein 1. J Biol Chem. 2008; 283:29658-70.
53. Kim JA, Åberg C, Salvati A, Dawson KA. Role of cell cycle on the cellular uptake and dilution of nanoparticles in a cell population. Nat Nanotechnol. 2011; 7:62-68.

54. Hu G, Cun X, Ruan S, Shi K, Wang Y, Kuang Q, Hu C, Xiao W, He Q, Gao H. Utilizing G2/M retention effect to enhance tumor accumulation of active targeting nanoparticles. Sci Rep. 2016; 6:27669.

55. Gao H, Hu G, Zhang Q, Zhang S, Jiang X, He Q. Pretreatment with chemotherapeutics for enhanced nanoparticles accumulation in tumor: the potential role of G2 cycle retention effect. Sci Rep. 2014; 4:4492.

56. Chen H, Niu X, Gao A, Zhang S. Mitochondrial signal peptide guides EGFP-GRP75 fusion proteins into mitochondria. [Article in Chinese] Xi Bao Yu Fen Zi Mian Yi Xue Za Zhi. 2016; 32:1311-1316.

57. Ma HT, Poon RY. Synchronization of HeLa cells. Methods Mol Biol. 2011; 761:151-61.

58. Santos A, Wernersson R, Jensen LJ. Cyclebase 3.0: a multiorganism database on cell-cycle regulation and phenotypes. Nucleic Acids Res. 2015; 43:D1140-44. 